\title{
Phytoprotection
}

\section{Impact environnemental des cultures transgéniques}

\author{
II. L'impact des caractères recombinants
}

\section{Environmental impact of transgenic crops}

\section{Impact of recombinant traits}

\section{Dominique Michaud}

Volume 86, numéro 2, août 2005

URI : https://id.erudit.org/iderudit/012511ar

DOI : https://doi.org/10.7202/012511ar

Aller au sommaire du numéro

Éditeur(s)

Société de protection des plantes du Québec (SPPQ)

ISSN

0031-9511 (imprimé)

1710-1603 (numérique)

Découvrir la revue

Citer cet article

Michaud, D. (2005). Impact environnemental des cultures transgéniques : iI. L'impact des caractères recombinants. Phytoprotection, 86(2), 107-124.

https://doi.org/10.7202/012511ar
Résumé de l'article

La publication d'un article scientifique sur les effets néfastes d'un hybride de maïs transgénique exprimant une $\delta$-endotoxine du Bacillus thuringiensis contre des larves du papillon monarque causait, il y a quelques années, une controverse sans précédent sur l'impact environnemental des caractères recombinants introduits au bagage génétique des cultures agricoles. Le présent article de synthèse, complémentaire à un article de ce même numéro abordant la migration des transgènes dans l'environnement (Michaud 2005), discute de l'impact des caractères recombinants encodés par les transgènes sur l'incidence et le développement des différents organismes vivants du milieu. L'impact des nouveaux caractères est d'abord considéré à l'échelle des écosystèmes, à la lumière des effets exercés par les pratiques agricoles courantes sur la diversité biologique au champ. L'impact de ces caractères est ensuite considéré en fonction des interactions spécifiques établies au champ ou en conditions de laboratoire entre la plante modifiée et une gamme d'espèces modèles incluant des ravageurs herbivores secondaires, des arthropodes prédateurs et différents organismes du sol.
Tous droits réservés @ La société de protection des plantes du Québec, 2005
Ce document est protégé par la loi sur le droit d'auteur. L’utilisation des services d'Érudit (y compris la reproduction) est assujettie à sa politique d'utilisation que vous pouvez consulter en ligne.

https://apropos.erudit.org/fr/usagers/politique-dutilisation/ 


\title{
Impact environnemental des cultures transgéniques II. L'impact des caractères recombinants
}

\author{
Dominique Michaud ${ }^{1}$
}

Reçu 2005-11-02; accepté 2005-11-18

PHYTOPROTECTION $86: 107-124$

La publication d'un article scientifique sur les effets néfastes d'un hybride de maïs transgénique exprimant une $\delta$-endotoxine du Bacillus thuringiensis contre des larves du papillon monarque causait, il y a quelques années, une controverse sans précédent sur l'impact environnemental des caractères recombinants introduits au bagage génétique des cultures agricoles. Le présent article de synthèse, complémentaire à un article de ce même numéro abordant la migration des transgènes dans l'environnement (Michaud 2005), discute de l'impact des caractères recombinants encodés par les transgènes sur l'incidence et le développement des différents organismes vivants du milieu. L'impact des nouveaux caractères est d'abord considéré à l'échelle des écosystèmes, à la lumière des effets exercés par les pratiques agricoles courantes sur la diversité biologique au champ. L'impact de ces caractères est ensuite considéré en fonction des interactions spécifiques établies au champ ou en conditions de laboratoire entre la plante modifiée et une gamme d'espèces modèles incluant des ravageurs herbivores secondaires, des arthropodes prédateurs et différents organismes du sol.

Mots clés : Biodiversité, cultures transgéniques, impact environnemental, interactions multitrophiques, protéines recombinantes.

\section{[Environmental impact of transgenic crops. II. Impact of recombinant traits]}

A scientific communication reporting the deleterious effects on monarch butterfly larvae of a transgenic corn hybrid expressing a Bacillus thuringiensis $\delta$-endotoxin has caused, a few years ago, an unprecedented controversy on the environmental impact of recombinant traits introduced into the genome of agricultural crops. This review, complementing a review in this same issue on transgene migration in the environment (Michaud 2005), addresses the impact of these new traits on the development and survival of different non-target living organisms present in the environment. The impact of these new traits is first considered at the ecosystem level, in relation with the effects of current agricultural practices on field biodiversity. The impact of these traits is then considered in relation with the specific interactions established in the field or under laboratory conditions between the modified plant and a collection of model organisms including secondary herbivorous pests, predatory arthropods and different species of the soil community.

Keywords: Biodiversity, environmental impact, multitrophic interactions, recombinant proteins, transgenic crops.

\section{INTRODUCTION}

La publication fort médiatisée d'une communication scientifique sur les effets néfastes d'un hybride de maïs transgénique contre le papillon monarque, Danaus plexippus (L.) [Lepidoptera : Danaidae] (Losey et al. 1999), causait, il y a quelques années, une controverse sans précédent sur l'impact environnemental des caractères recombinants introduits au bagage génétique des cultures agricoles (Pimentel et Raven 2000; Shelton et Sears 2001). Cette étude s'intéressait aux effets secondaires possibles d'hybrides de maïs transgéniques exprimant une $\delta$-endotoxine de la bactérie du sol Bacillus thuringiensis (Bt), la protéine Cry1Ab, développés à la base pour la répression d'un insecte ravageur répandu, la pyrale du maïs Ostrinia nubilalis Hübner [Lepidoptera : Pyralidae]. Réalisée en laboratoire et appuyée par des tests similaires effectués en partie en champ (Hansen Jesse et Obrycki 2000), cette étude rapportait que I'un des hybrides étudiés, I'hybride Event 176, était toxique pour les larves du papillon nourries de feuilles d'asclépiade (Asclepias syriaca L.) enduites d'une

1. Centre de recherche en horticulture, Université Laval, Québec (Québec), Canada G1K 7P4; courriel : dominique.michaud@ crh.ulaval.ca 
forte quantité de pollen isolé de cet hybride. Ces observations, explicables par la toxicité démontrée des toxines CrylA contre les Lépidoptères et I'abondance particulièrement élevée de la protéine Cry1Ab dans le pollen de I'hybride testé (Hellmich et al. 2001; Pimentel et Raven 2000), soulevaient la question des effets secondaires possibles associés aux cultures transgéniques résistantes aux ravageurs herbivores sur les organismes non ciblés retrouvés dans le milieu. Alors que des études ultérieures démontraient finalement un effet négligeable des hybrides commerciaux de maïs Bt sur le papillon monarque en contexte agricole (Gatehouse et al. 2002; Shelton et Sears 2001; Stanley-Horn et al. 2001), ce nouvel épisode du débat sur les végétaux transgéniques contribuait à catalyser la poursuite des efforts de recherche sur la question complexe de l'impact environnemental des caractères recombinants introduits au génome de ces organismes. De nombreuses études ont été publiées ces dernières années sur l'effet des caractères recombinants sur les organismes du milieu et, dans une perspective plus large, sur I'impact de l'adoption des plantes transgéniques sur les pratiques culturales et la diversité biologique dans les agroécosystèmes (Clark et al. 2005; Dunfield et Germida 2004; Firbank et al. 2003; Groot et Dicke 2002; Kowalchuk et al. 2003; Losey et al. 2004a, b; O'Callaghan et al. 2005). En complément à un article traitant de la migration des transgènes dans l'environnement (Michaud 2005), cet article de synthèse aborde l'impact des cultures transgéniques et des caractères recombinants exprimés sur les organismes du milieu, à la lumière des pratiques agricoles actuelles et du concept général de biodiversité.

Qu'elles croissent en milieu naturel ou qu'elles soient le fruit d'un programme d'amélioration génétique, les plantes exercent une influence marquée sur leur environnement parce qu'elles interagissent de façon dynamique avec une gamme d'organismes prédateurs, pathogènes, pollinisateurs ou symbiontes. Les plantes contribuent aussi à façonner leur environnement en altérant les propriétés physiques, chimiques et biologiques du sol par l'intermédiaire de leur système racinaire. La déposition naturelle de matériel végétal à la surface du sol pendant la saison de croissance ou l'application de résidus de culture dans le sol pour l'amender en matière organique ont aussi une influence significative sur les éléments du milieu. D'un point de vue agronomique, la conversion d'un site naturel en terre agricole a un impact marqué sur les propriétés du sol et la diversité biologique au champ, tout comme des pratiques culturales courantes comme l'application de fertilisants, les rotations de cultures, le labour, la lutte aux mauvaises herbes ou l'application d'insecticides (Robinson et Sutherland 2002; Wilson et al. 1999). Le choix des variétés végétales ensemencées à la ferme a aussi une incidence importante sur les populations microbiennes du sol à proximité des racines (Siciliano et al. 1998), illustrant encore une fois la nature complexe et dynamique des processus physicochimiques et biologiques en milieu agricole, la grande plasticité des agroécosystèmes et l'impact marqué des pratiques culturales sur l'environnement.

\section{IMPACT DES CULTURES TRANSGÉNIQUES SUR LE MILIEU}

Dans ce contexte, les impacts environnementaux associés aux cultures transgéniques doivent être considérés sur une base comparative, par une identification des effets divergents associés à ces cultures et à leurs contreparties isogéniques conventionnelles. Considérant la diversité et la spécificité variable des caractères recombinants, la complexité des interactions biotiques à l'échelle des écosystèmes et la nature aléatoire du processus d'insertion des transgènes au génome de la plante hôte, les impacts environnementaux associés aux plantes transgéniques pourront résulter: (i) d'un spectre d'action biologique non spécifique du produit recombinant exprimé; (ii) d'une altération des composantes de la plante hôte résultant de l'insertion ou de l'expression du transgène; (iii) de l'impact du nouveau caractère sur la prépondérance des différents organismes, incluant la plante modifiée, dans l'écosystème considéré.

i. Spectre d'action du produit recombinant. Bien que la spécificité des caractères recombinants introduits au génome des plantes transgéniques permette en principe de limiter leur action à des cibles précises, des effets éventuels sur d'autres organismes ne peuvent être exclus dans tous les cas. Le cas du papillon monarque et de la toxine Cry1Ab est un exemple désormais classique illustrant la spécificité préférentielle mais non absolue d'un caractère recombinant contre une cible herbivore (Pimentel et Raven 2000). Comme la protéine Cry1Ab, d'autres toxines du Bt montrent un spectre d'action préférentiel contre certains insectes lépidoptères, mais sont toxiques à fortes doses contre des espèces apparentées (v. par ex. : Sims 1995, 1997). De même, des caractères recombinants alternatifs maintenant considérés pour la répression des ravageurs herbivores pourraient montrer des effets sur les organismes non ciblés en raison de leur spécificité parfois limitée (v. plus loin : Spécificité des produits recombinants et mutagénèse insertionnelle).

ii. Altération des composantes de la plante hôte. Le processus de transgénèse permet l'intégration de nouveaux caractères par l'ajout d'une quantité minimale de matériel génétique, mais le lieu d'insertion du transgène demeure le plus souvent aléatoire (Gelvin 2003). Dans la plante modifiée, le site d'insertion du transgène pourra influencer son expression et celle de gènes résidants. Les taux d'expression variables du transgène, observés couramment d'un clone transgénique à l'autre pour une même construction génétique, seraient expliqués par l'influence de son environnement immédiat au sein du bagage génétique de I'hôte. De même, le transgène pourra influencer l'expression de gènes résidants par l'intermédiaire des séquences régulatrices incluses dans les constructions géniques ou parce que son insertion aura compromis leur intégrité physique, avec un impact éventuel sur les caractéristiques de la plante, indépendamment de l'activité du produit recombinant (Elmore et al. 2001; Masoero et al. 1999; Saxena et Stotzky 2001a). À ces phénomènes de mutagénèse insertionnelle pourront s'ajouter, le 
cas échéant, des phénomènes pléiotropiques lou d'interférence métabolique) liés à l'activité biologique de la protéine recombinante encodée par le transgène. Si des protéines recombinantes répandues comme les $\delta$-endotoxines du $\mathrm{Bt}$ ou des enzymes de détoxification des herbicides montrent une spécificité élevée envers des cibles précises, d'autres protéines pourraient montrer, en marge de l'effet prévu, des effets plus étendus modifiant la composition ou les caractéristiques physiques de la plante hôte par un impact direct sur son métabolisme ou son développement ( $v$. par ex. : Gutierez-Campos et al. 2001; Van der Vyver et al. 2003).

iii. Impact écosystémique du caractère introduit. La presque totalité des cultures transgéniques introduites jusqu'ici en milieu agricole sont destinées à la répression des mauvaises herbes ou des insectes herbivores (James 2005). Par définition, toute mesure de phytoprotection adoptée à la ferme a un impact direct sur les différentes espèces retrouvées sur le site traité. Comme les herbicides, les plantes transgéniques développées pour la répression des mauvaises herbes pourront avoir un impact négatif important sur le nombre d'espèces végétales présentes, avec un effet à la baisse sur la diversité des refuges et des sources de nourriture disponibles dans le milieu (Firbank et al. 2003; Robinson et Sutherland 2002). En outre, la répression des insectes herbivores par la culture de variétés transgéniques résistantes pourra, comme les insecticides, influencer les équilibres établis entre les différentes populations constituantes, avec des conséquences tangibles sur I'incidence relative des ravageurs secondaires, des insectes auxiliaires, des arthropodes du sol et des organismes s'en nourrissant (Losey et al. 2004a, b; Robinson et Sutherland 2002). Le caractère recombinant nouvellement exprimé pourra aussi avoir un impact sur les populations du milieu en conférant à la plante modifiée un avantage sélectif favorisant son implantation en milieu agricole ou naturel (v. Michaud 2005).

Au bilan, I'ensemble des effets associés à une culture transgénique déterminera son impact net, positif ou négatif, sur l'environnement. Étant donné l'influence marquée des pratiques agricoles sur le milieu et la multiplicité de facteurs à considérer pour une analyse exhaustive des interactions biotiques à l'échelle des écosystèmes, l'impact des cultures transgéniques sur l'environnement est généralement estimé sur une base relative plutôt qu'absolue, à la lumière des impacts exercés par les pratiques agricoles courantes. L'idée n'est pas de déterminer si la plante modifiée montrera - comme toutes les plantes - des effets sur son milieu, mais plutôt d'évaluer les conséquences relatives des effets mesurés dans un contexte agricole. Plusieurs études empiriques sur l'impact agroenvironnemental des cultures transgéniques se sont attardées à leurs effets sur la croissance et le développement d'espèces modèles variées incluant des ravageurs secondaires, des agents pollinisateurs et des organismes du sol. D'autres études ont considéré ces effets dans une perspective plus large, s'attardant en particulier aux processus physicochimiques majeurs et à la diversité biologique caractéristiques des écosystèmes.

\section{ÉQUILIBRES ÉCOSYSTÉMIQUES ET DIVERSITÉ BIOLOGIQUE AU CHAMP}

Une inquiétude souvent formulée au sujet des cultures transgéniques réfère à leurs conséquences négatives possibles sur la diversité biologique (ou "biodiversité ") dans l'environnement. Selon certains, la culture de variétés transgéniques est un nouveau type d'agriculture dont la maîtrise limitée et déficiente pourrait compromettre l'intégrité du taux de biodiversité dans le milieu et la pérennité des systèmes agricoles adoptés dans un contexte de développement durable (Garcia et Altieri 2005). Aujourd'hui reconnu mondialement, le concept de biodiversité demeure complexe et difficile à définir. Selon la Convention sur la diversité biologique (CBD 1992), la biodiversité réfère à la variété d'organismes vivants de toutes natures - ailés, terrestres et aquatiques - au sein d'un écosystème, tenant compte aussi bien de la variabilité intraspécifique que de l'incidence relative des espèces constituantes. D'autres définitions ont aussi été proposées, mettant tour à tour l'accent sur la diversité des écosystèmes et des biotopes, la diversité des espèces recensées ou la diversité génétique globale dans le milieu considéré (Jenkins 1992; OECD 1996; OTA 1988). Souvent estimée, en pratique, par le nombre d'espèces animales, végétales et microbiennes présentes (OECD 1996), la biodiversité d'un milieu donné apparaît importante à plusieurs égards. Sous un angle utilitaire ou économique, elle est à l'origine d'une multitude de produits importants comme les aliments, les fibres, les ressources énergétiques, plusieurs médicaments et des composés chimiques variés (Pimentel et al. 1997; ten Kate et Laird 1999). Sous un angle plus philosophique, la biodiversité est liée à un ensemble de valeurs esthétiques, scientifiques et culturelles essentielles pour une société saine et florissante (Kunin et Lawton 1996; Lockwood 1999).

\section{Agriculture et biodiversité}

Dans un sens plus spécifique, le concept d' « agrobiodiversité " a été proposé pour une prise en compte mieux adaptée au contexte agricole (Hardon et al. 2000). L'agriculture moderne est le résultat d'un long processus de domestication et de sélection des végétaux, de leur culture sur une base sédentaire et de l'amélioration dirigée de leurs caractéristiques à diverses fins. Au cours du temps, de nombreuses espèces animales, végétales et microbiennes ont adopté les milieux agricoles comme principale niche écologique, co-évoluant avec les plantes cultivées et contribuant à façonner les (agro)écosystèmes riches et complexes observés en milieux ruraux (Hardon et al. 2000; Robinson et Sutherland 2002). L'agrobiodiversité caractéristique d'un site agricole, influencée par des facteurs abiotiques comme le climat, la topographie ou la nature du sol, est aussi modelée par les pratiques adoptées à la ferme, qu'il s'agisse du choix des cultures et des variétés ensemencées, des plans de fertilisation appliqués au sol ou des mesures phytosanitaires mises en place pour la répression des mauvaises herbes, des arthropodes nuisibles ou des agents pathogènes (Wilson et al. 1999). 
La richesse des agroécosystèmes s'est toutefois amenuisée de façon marquée au cours des dernières décennies avec l'industrialisation et la spécialisation croissantes des exploitations agricoles (Robinson et Sutherland 2002). Historiquement, la mise au point de variétés végétales répondant toujours mieux aux contraintes agroéconomiques exercées sur les agriculteurs a modelé l'évolution des systèmes agricoles, avec un impact direct sur les composantes du milieu. L'amélioration génétique des cultures et les pratiques agricoles courantes, en particulier, ont souvent été régies par des impératifs agroéconomiques, avec pour résultat une diminution graduelle du nombre d'espèces et de variétés cultivées, un appauvrissement du patrimoine génétique des cultures majeures, un accroissement rapide de la taille et du degré de spécialisation des exploitations agricoles et un effet à la baisse de ces différents facteurs sur les populations animales recensées en milieu agricole (Pretty 1995; Wilson et al. 1999). D'un point de vue plus global, l'évolution récente de l'agriculture a aussi suivi un cheminement axé sur l'uniformisation des ressources. Alors que des milliers d'espèces végétales ont été utilisées à travers le temps à des fins alimentaires (Ehrlich et Wilson 1991), une vingtaine d'espèces seulement contribuent aujourd'hui à $90 \%$ des produits végétaux désormais utilisés à l'échelle mondiale (Solbrig 1992). De ces espèces, quatre seulement - le blé, le maïs, le riz et la pomme de terre constituent aujourd'hui $50 \%$ de la production agricole mondiale et 15 espèces en constituent les deux tiers (Gotsch et Rieder 1995). Dans un tel contexte, des variétés transgéniques comme les cultures tolérantes aux herbicides ou les plantes Bt résistantes aux insectes pourront être assimilées à des modes de culture d'abord voués à la recherche de hauts rendements et associées de facto à l'ensemble des contraintes exercées par l'agriculture sur la biodiversité.

\section{Impact des cultures transgéniques sur la biodiversité}

L'impact spécifique des cultures transgéniques apparaît par contre plus mitigé à l'échelle des agroécosystèmes. Considérant le nombre d'espèces vivantes recensées comme un indicateur fiable du taux de biodiversité (OECD 1996), l'impact d'une culture transgénique sur la diversité biologique au champ est établi en comparant l'incidence relative des espèces recensées sur le site considéré à celle des espèces retrouvées en systèmes conventionnels. En théorie, des cultures transgéniques auront des effets sur le milieu et la biodiversité : (i) en raison de la mise en oeuvre des gestions de cultures associées à leur utilisation; ou (ii) par les effets directs ou indirects de leurs nouveaux caractères sur les organismes du milieu.

Des études exhaustives ont été menées en GrandeBretagne au début des années 2000 pour mesurer l'impact des cultures tolérantes aux herbicides sur l'incidence d'une gamme d'organismes animaux et végétaux dans les champs agricoles et les sites environnants (Firbank et al. 2003; Perry et al. 2003). Réalisées sur une période de trois ans sur des dizaines de sites à l'échelle du pays, ces études ont démontré dans l'ensemble un effet significatif de la gestion des cultures associée aux lignées modifiées, comparativement aux impacts mesurés sur des par- celles témoins ensemencées de lignées conventionnelles traitées avec les herbicides de synthèse normalement utilisés (Bohan et al. 2005; Brooks et al. 2003; Champion et al. 2003; Haughton et al. 2003; Hawes et al. 2003; Heard et al. 2003a, b; Roy et al. 2003). Ces impacts, indépendants du processus de transgénèse ou du caractère recombinant exprimé, étaient plutôt liés à l'efficacité du désherbage pour les différents types de gestion (Firbank 2003). Alors que la biodiversité était affectée à la baisse dans les cas du canola et de la betterave transgéniques en raison de taux d'éradication des mauvaises herbes plus efficaces, la situation inverse était observée pour le maïs parce que la gestion conventionnelle de désherbage était plus efficace, avec cette fois un impact moindre sur le milieu en faveur des hybrides transgéniques. Les différences observées d'un cas à l'autre étaient directement liées, en somme, au nombre d'espèces végétales toujours présentes suite au désherbage et à la variété de refuges et de sources alimentaires encore disponibles dans le milieu.

L'impact des cultures transgéniques Bt sur la biodiversité a aussi fait l'objet de plusieurs études récentes, avec comme hypothèse générale des effets directs ou indirects possibles de ces plantes sur les populations d'organismes non ciblés par la toxine recombinante (Clark et al. 2005). Alors que l'impact négatif d'un hybride de maïs Bt sur la survie du papillon monarque était observé en laboratoire (Losey et al. 1999), aucun effet de ces hybrides n'était observé au champ sur plusieurs populations de coléoptères (Lozzia 1999). Des études subséquentes suggéraient dans l'ensemble des effets négligeables du maïs Bt sur l'incidence des arthropodes herbivores secondaires, des insectes carnivores et des populations d'arthropodes du sol (Bourguet et al. 2002; Candolfi et al. 2004; Jasinski et al. 2003). Le suivi systématique d'acariens du sol et d'une quinzaine d'arthropodes bénéfiques dans les champs de l'Ohio, aux États-Unis, a mené à des conclusions semblables pour différentes lignées transgéniques de maïs et de soja résistantes aux insectes ou tolérantes aux herbicides (Jasinski et al. 2003), suggérant de nouveau des effets limités de ces cultures modifiées dans les écosystèmes agricoles.

Ces conclusions suggérant un impact négligeable des cultures transgéniques sur la biodiversité n'entament toutefois pas la pertinence d'études additionnelles situant la question dans un contexte plus large. Une difficulté inhérente à l'étude des écosystèmes tient du fait que l'échelle spatio-temporelle généralement adoptée pour les études ne correspond pas à l'échelle réelle (Freckleton et al. 2004). Alors que des études "réalistes " à l'échelle d'une région devraient idéalement s'appuyer sur des données prises sur I'ensemble de cette région et sur des périodes de plusieurs années (Watkinson et al. 2000), les études réalisées sur le sujet s'appuient le plus souvent sur des données récoltées sur des sites spécifiques pendant deux ou trois ans. S'il apparaît irréaliste et improductif, pour des raisons de financement et de pertinence, d'entreprendre des études exhaustives à long terme pour toutes les questions posées, I'acquisition de nouvelles données empiriques spécifiques à chaque culture majeure et l'accès à des procédures plus puissantes pour l'analyse des données apparaîtront souhaitables, dans les années à venir, pour 
tirer des conclusions sans cesse plus fidèles de la réalité complexe des agroécosystèmes (Bourguet et al. 2002). La très grande variété d'arthropodes dans des cultures agricoles pourtant très homogènes comme le maïs (Losey et al. 2003) rendra également souhaitable la définition de stratégies rationnelles pour un choix judicieux des espèces modèles étudiées (Dutton et al. 2003). À plus petite échelle, une compréhension accrue des interactions possibles entre les variétés transgéniques et différents organismes modèles représentatifs du milieu permettront une prise en compte et une modulation plus fines des effets éventuels, négatifs ou positifs, exercés par les nouveaux caractères recombinants. De nombreuses études en milieu contrôlé publiées ces dernières années au sujet de l'impact des plantes transgéniques sur la croissance et le développement d'organismes modèles variés contribuent aujourd'hui à notre compréhension des interactions et des phénomènes possibles dans l'environnement.

\section{EFFETS DES LIGNÉES TRANSGÉNIQUES SUR LES ORGANISMES DU MILIEU}

En théorie, les plantes transgéniques peuvent montrer des effets sur les organismes du milieu : (i) par voie directe, en établissant un lien fonctionnel avec les organismes touchés; ou (ii) par voie indirecte, en exerçant leur influence par l'intermédiaire d'un organisme tiers avec lequel elles auront interagi au préalable. En plus de montrer des effets sur l'insecte herbivore ciblé, des hybrides de maïs Bt pourront par exemple influencer le développement ou le comportement d'organismes comme les insectes pollinisateurs, les bactéries symbiontes, les organismes détritivores, les agents pathogènes ou d'autres organismes phytophages consommant leurs tissus ou des produits dérivés (Fig. 1). De manière indirecte, elles pourront affecter des organismes prédateurs, parasites ou pathogènes utilisant comme proie ou comme hôte l'insecte herbivore nourri de matériel transgénique.

\section{Impacts directs sur les arthropodes herbivores et pollinisateurs}

Plusieurs études ont été menées pour évaluer l'impact des cultures transgéniques sur les arthropodes phytophages non ciblés par le composé recombinant, avec comme modèle végétal dans la plupart des cas des lignées exprimant une toxine Cry du Bt. Non toxiques pour les mammifères (McClintock et al. 1995) et sans incidence mesurable sur la croissance et le rendement des animaux de ferme (Folmer et al. 2002), ces bioinsecticides sont généralement considérés comme étant très spécifiques, avec une action limitée à certains insectes (Sims 1997; Sims et Martin 1997) ou nématodes (Marroquin et al. 2000). Cette spécificité élevée des toxines Cry, qui contribue à leur popularité en phytoprotection, n'assure toutefois pas une absence systématique d'effets secondaires dans le milieu. La toxine Cry1Ac purifiée d'une lignée de coton transgénique, par exemple, s'est avérée bénigne en laboratoire pour une dizaine d'insectes herbivores ou prédateurs non ciblés, mais toxique à fortes doses contre plusieurs insectes lépidoptères apparentés à l'insecte visé (Sims 1995). De manière similaire, les études initiales rapportant des effets négatifs du maïs $\mathrm{Bt}$ sur le papillon monarque (Hansen Jesse et Obrycki 2000; Losey et al. 1999) ont été appuyées par des travaux en champ confirmant l'impact négatif de I'hybride Event 176, retiré du marché en 2001, sur les larves du papillon (Stanley-Horn et al. 2001; Zangerl et al. 2001). Si des facteurs variés comme le faible taux d'expression de la toxine Cry1 $A b$ dans les lignées de maïs $B t$ actuellement disponibles, la faible quantité de pollen déposée sur les feuilles d'asclépiade dans les champs ou la préférence des adultes pour des feuilles d'asclépiade sans pollen au moment de la ponte (Oberhauser et al. 2001; Pleasants et al. 2001; Tschenn et al. 2001) suggèrent des impacts négligeables de ces hybrides sur le papillon en comparaison aux effets négatifs des mesures phytosanitaires adoptées pour la répression des mauvaises herbes et des insectes en systèmes conventionnels (Gatehouse et al. 2002; Sears et al. 2001; Shelton et Sears 2001; Wolt et al. 2003), de nouvelles données empiriques sur les interactions possibles

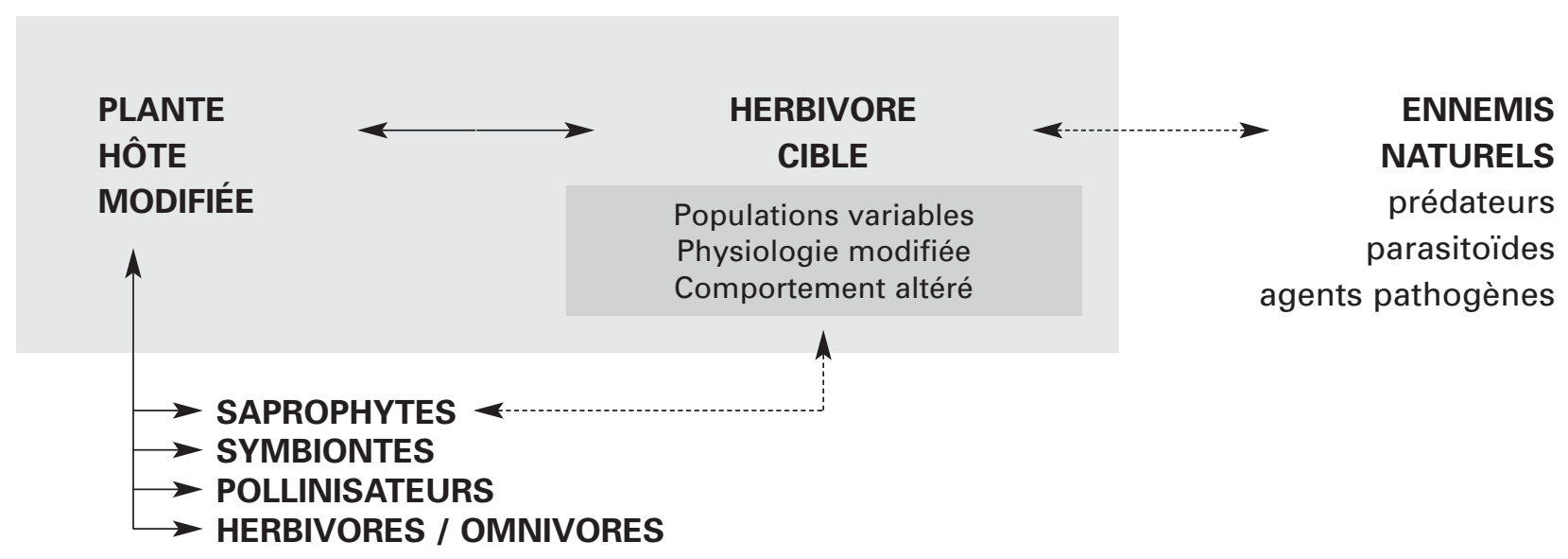

Figure 1. Impact des cultures transgéniques résistantes aux insectes herbivores sur les organismes non ciblés - Une illustration schématique des niveaux d'interférence possibles. Les flèches pleines indiquent une interaction directe avec la plante modifiée, les flèches pointillées une interaction indirecte. 
au champ s'avèreront utiles pour une description toujours plus juste de l'impact relatif des cultures modifiées et de leurs contreparties conventionnelles sur les organismes du milieu.

Les différentes études menées en laboratoire et en champ concernant l'impact des cultures transgéniques Bt sur la croissance, le développement ou la survie des arthropodes herbivores non ciblés ont conduit à des conclusions variables en fonction : (i) du degré de parenté entre l'insecte cible et l'organisme non ciblé; (ii) de la nature de l'interaction entre l'organisme étudié et la plante modifiée; et (iii) de la lignée végétale utilisée pour les tests (Tableau 1). En lien avec l'action des toxines du Bt contre certains groupes d'insectes, des effets négatifs ont été notés dans les cas où l'espèce considérée était apparentée à l'insecte visé par la toxine exprimée. Pour les hybrides de maïs exprimant la toxine Cry1Ab, par exemple, des effets négatifs ont été observés contre certains lépidoptères apparentés à la pyrale du maïs (Felke et al. 2002; Hansen Jesse et Obrycki 2000; Losey et al. 1999; Pilcher et al. 1997a; Stanley-Horn et al. 2001; Zangerl et al. 2001), alors qu'aucun effet significatif n'était observé, en champ comme en laboratoire, pour une gamme d'espèces plus éloignées incluant des pucerons, des acariens et divers arthropodes omnivores (Duan et al. 2002; Head et al. 2001; Lozzia et al. 1998, 2000; Lumbierres et al. 2004; Lundgren et Wiedenmann 2002; Obrist et al. 2005; Pilcher et al. 1997b). Dans le cas d'une ingestion de toxine via le pollen, les impacts négatifs observés pour certains lépidoptères étaient associés systématiquement à I'hybride Event 176 (Felke et al. 2002; Hansen Jesse et Obrycki 2000; Losey et al. 1999; Stanley-Horn et al. 2001; Zangerl et al. 2001), reconnu pour sa teneur élevée en protéine recombinante dans les tissus du pollen. À l'opposé, les hybrides commerciaux Bt11 et Mon810 montraient des effets négligeables sur les mêmes espèces, corrélés à une faible teneur en protéine recombinante dans le pollen (Stanley-Horn et al. 2001; Wraight et al. 2000). Ces données confirmaient, en somme, la spécificité des effets toxiques causés par la toxine dans l'hybride Event 176 et soulignaient les faibles risques associés au pollen des hybrides commerciaux contre les insectes non ciblés sensibles à cette protéine (Sears et al. 2001).

Des tests menés sur des insectes pollinisateurs comme I'abeille domestique (Apis mellifera L.) [Hymenoptera : Apidae] ou le bourdon terrestre (Bombus terrestris L.) [Hymenoptera : Apidae] appuyaient également l'idée d'un impact négligeable des plantes transgéniques $\mathrm{Bt}$ sur les organismes non ciblés (O'Callaghan et al. 2005). Bien que la pollinisation de cultures comme le maïs ou le coton ne dépende pas des abeilles, ces insectes sont parfois attirés par ces plantes et peuvent entrer en interaction avec des lignées transgéniques Bt. Selon les données actuelles, les toxines Cry exprimées dans les plantes transgéniques sont toutefois sans effet, même à fortes doses, sur la croissance et le développement des abeilles domestiques et des bourdons terrestres (EPA 2000; Malone et Pham-Delègue 2001, 2002). Ces observations, en accord avec l'impact limité des lignées transgéniques Bt sur ces organismes (PhamDelègue et al. 2002), n'excluent pas, par contre, la pertinence d'études additionnelles sur le sujet, tenant compte notamment de variables comportementales liées aux relations fonctionnelles et sociales complexes établies chez ces espèces dans l'environnement (Malone et Burgess 2000).

\section{Impacts directs sur les organismes du sol}

Des études additionnelles seront également utiles pour une compréhension plus fine de l'impact des cultures transgéniques sur les populations du sol et I'ensemble des processus biochimiques qui en dépendent (Bruinsma et al. 2003; Dunfield et Germida 2004; Kowalchuk et al. 2003; Motavalli et al. 2005). Partie intégrante des écosystèmes, les sols abritent une variété d'organismes incluant de nombreuses espèces bactériennes et fongiques, des nématodes, des protozoaires et une microfaune active composée entre autres de vers de terre, de collemboles, d'acariens et d'isopodes (Kowalchuk et al. 2003; O'Callaghan et al. 2005). Ensemble, ces organismes forment un réseau biotique complexe qui assure le fonctionnement de processus importants pour les écosystèmes, comme la décomposition de la matière organique, le recylcage des éléments nutritifs, la fixation de l'azote atmosphérique et la solubilisation des minéraux (Motavalli et al. 2005). Comme toute plante cultivée, les cultures transgéniques pourront entrer en interaction avec les organismes du sol par différentes voies, via leur système racinaire ou par les résidus de culture relâchés en saison ou appliqués au sol après la récolte. Les protéines recombinantes, excrétées dans le sol par les exsudats racinaires des plantes en culture (Borisjuk et al. 1999; Saxena et Stotzky 2001a; Saxena et al. 1999, 2002, 2004) ou libérées des tissus de la plante en décomposition (Saxena et Stotzky 2001a; Saxena et al. 2004), pourront s'adsorber aux particules argileuses du sol et montrer des effets éventuels sur les espèces résidantes, en fonction de leur spécificité d'action et de leur stabilité dans l'environnement édaphique.

Plusieurs études ont été menées pour évaluer la persistance des protéines recombinantes dans les sols, en particulier dans le cas des toxines Cry du Bt. Selon les propriétés physicochimiques et la teneur en matière organique du sol, les conditions ambiantes et leurs caractéristiques propres, les protéines recombinantes montrent une stabilité très variable une fois relâchées des tissus végétaux, disparaissant du sol en quelques jours (Herman et al. 2002; Hopkins et Gregorich 2003; Palm et al. 1994; Sims et Holden 1996; Sims et Ream 1997) ou demeurant stables, à l'inverse, sur de longues périodes (Baumgarte et Tebbe 2005; Crecchio et Stotzky, 1998, 2001; Donegan et al. 1997; Tapp et Stotzky 1998; Zwahlen et al. 2003a). Considérant l'expression constitutive des transgènes dans la plupart des variétés transgéniques présentement sur le marché, cette stabilité différentielle des protéines recombinantes pourrait toutefois ne pas être déterminante dans un contexte agricole, alors que le relargage de protéines dans le sol à partir de la plante pourrait se faire de manière continue en cours de saison. Dans un sol cultivé, même des protéines rapidement dégradées par la flore et la faune résidantes, au point de n'être pas détectables après plusieurs années de culture (Head et al. 2002), pourraient en théorie s'y retrouver sur 
MICHAUD: IMPACT DES PROTÉINES RECOMBINANTES SUR L'ENVIRONNEMENT

Tableau 1. Impact des cultures transgéniques Bt sur des arthropodes non ciblés - Un résumé des études récentes en laboratoire et en champ

\begin{tabular}{|c|c|c|c|c|}
\hline Culture / Toxine & Espèce modèle & Dispositif & Effets $^{1}$ & Référence \\
\hline & \multicolumn{4}{|c|}{ CONSOMMATION DU TISSU VÉGÉTAL OU DE LA SĖVE (PHYTOPHAGES SECONDAIRES OU OMNIVORES) } \\
\hline \multirow[t]{12}{*}{ Maïs / Cry1Ab } & Agrotis ipsilon ${ }^{2}$ & En laboratoire & Négligeables & Pilcher et al. 1997a \\
\hline & & En champ & Négligeables & Pilcher et al. 1997a \\
\hline & Frankliniella tenuicornis & En laboratoire & Négligeables & Obrist et al. 2005 \\
\hline & Heliothis zea² & En champ & Négatifs & Pilcher et al. 1997a \\
\hline & Papaipema nebris ${ }^{2}$ & En laboratoire & Négligeables & Pilcher et al. 1997a \\
\hline & & En champ & Négligeables & Pilcher et al. 1997a \\
\hline & Pseudaletia unipuncta ${ }^{2}$ & En laboratoire & Négatifs & Pilcher et al. 1997a \\
\hline & & En champ & Négatifs & Pilcher et al. 1997a \\
\hline & Rhopalosiphum maidis & En laboratoire & Négligeables & Head et al. 2001 \\
\hline & R. padi & En laboratoire & Négligeables & Lozzia et al. 1998 \\
\hline & & & & Lumbierres et al. 2004 \\
\hline & Tetranychus urticae ${ }^{6}$ & En laboratoire & Négligeables & Lozzia et al. 2000 \\
\hline Maïs / Cry3Bb1 & Rhizoglypus robini & En laboratoire & Négligeables & Carter et al. 2004 \\
\hline Pomme de terre / & Geocoris punctipes ${ }^{3}$ & En laboratoire & Négligeables & Armer et al. 2000 \\
\hline \multirow[t]{4}{*}{ Cry3A } & G. pallens ${ }^{3}$ & En laboratoire & Négligeables & Armer et al. 2000 \\
\hline & Orius tristicolor ${ }^{3}$ & En laboratoire & Négligeables & Armer et al. 2000 \\
\hline & Nabis spp. ${ }^{3}$ & En laboratoire & Négligeables & Armer et al. 2000 \\
\hline & CONSOMmation DU POLLEN & ORES ET POLLINISAT & & \\
\hline \multirow[t]{17}{*}{ Maïs / Cry1Ab } & Apis mellifera ${ }^{4}$ & En laboratoire & Négligeables & Pham-Delègue et al. 2002 \\
\hline & Coleomegilla maculata ${ }^{3}$ & En laboratoire & Négligeables & Pilcher et al. 1997b \\
\hline & & En champ & Négligeables & Pilcher et al. 1997b \\
\hline & Chrysoperla carnea ${ }^{3}$ & En laboratoire & Négligeables & Pilcher et al. 1997b \\
\hline & & En champ & Négligeables & Pilcher et al. 1997b \\
\hline & Danaus plexippus ${ }^{2}$ & En laboratoire & Négatifs ${ }^{6}$ & Losey et al. 1999 \\
\hline & & En champ ${ }^{5}$ & Négatifs ${ }^{6}$ & Hansen Jesse et Obrycki 2000 \\
\hline & & & Négatifs ${ }^{6}$ & Stanley-Horn et al. 2001 \\
\hline & & & & Zangerl et al. 2001 \\
\hline & & & Négligeables ${ }^{7}$ & Stanley-Horn et al. 2001 \\
\hline & Orius insidiosus ${ }^{3}$ & En laboratoire & Négligeables & Pilcher et al. 1997b \\
\hline & & En champ & Négligeables & Pilcher et al. 1997b \\
\hline & Papilio polyxenes ${ }^{2}$ & En champ & Négligeables & Wraight et al. 2000 \\
\hline & & En champ & Négatifs $^{6}$ & Zangerl et al. 2001 \\
\hline & Pieris brassicae ${ }^{2}$ & En laboratoire & Négatifs $^{6}$ & Felke et al. 2002 \\
\hline & P. rapae ${ }^{2}$ & En laboratoire & Négatifs $^{6}$ & Felke et al. 2002 \\
\hline & Plutella xylostella ${ }^{2}$ & En laboratoire & Négatifs ${ }^{6}$ & Felke et al. 2002 \\
\hline \multirow[t]{2}{*}{ Maïs / Cry3B } & C. maculata ${ }^{3}$ & En laboratoire & Négligeables & Lundgren et Wiedenmann 2002 \\
\hline & & & & Duan et al. 2002 \\
\hline
\end{tabular}

Effets mesurés sur la croissance, le développement ou la survie de l'espèce étudiée.

2 Insecte herbivore de l'ordre des Lépidoptères.

3 Insecte prédateur omnivore.

${ }_{4}$ Insecte pollinisateur.

5 Design expérimental hybride : échantillons foliaires d'asclépiade préparés en laboratoire et déposés au champ, à proximité de parcelles de maïs.

${ }_{6}^{6}$ Tests effectués avec l'hybride Event 176, retiré du marché en 2001 à l'expiration de son certificat d'enregistrement.

7 Tests effectués avec les hybrides Bt11 et Mon810. 
Tableau 2. Impact des cultures transgéniques sur les organismes du sol - Un sommaire des études récentes en laboratoire et en champ

\begin{tabular}{|c|c|c|c|}
\hline Culture / Caractère & Populations ou processus étudiés & Effets $^{1}$ & Référence \\
\hline \multicolumn{4}{|l|}{ Betterave à sucre } \\
\hline tolérance aux herbicides & Communautés bactériennes & n.s. & Schmalenberger et Tebbe 2003 \\
\hline \multicolumn{4}{|l|}{ Canola } \\
\hline \multirow[t]{3}{*}{ tolérance aux herbicides } & Communautés bactériennes & Mineurs & Dunfield et Germida 2001, 2003 \\
\hline & Communautés bactériennes & Mineurs & Siciliano et Germida 1999 \\
\hline & Communautés bactériennes & Mineurs & Gyamfi et al. 2002 \\
\hline \multicolumn{4}{|l|}{ Coton } \\
\hline protéine insecticide $(\mathrm{Bt})$ & Microflore du sol & Mineurs & Donegan et al. 1995 \\
\hline \multicolumn{4}{|l|}{ Luzerne } \\
\hline production d' $\alpha$-amylase & $\begin{array}{l}\text { Communautés bactériennes et fongiques, } \\
\text { nématodes, protozoaires, microarthropodes } \\
\text { et respiration microbienne }\end{array}$ & n.s. & Donegan et al. 1999 \\
\hline $\begin{array}{l}\text { production de lignine } \\
\text { (peroxydase) }\end{array}$ & $\begin{array}{l}\text { Communautés bactériennes et fongiques, } \\
\text { nématodes, protozoaires, microarthropodes } \\
\text { et respiration microbienne }\end{array}$ & Mineurs & Donegan et al. 1999 \\
\hline \multicolumn{4}{|l|}{ Maïs } \\
\hline tolérance aux herbicides & Communautés bactériennes & n.s. & Schmalenberger et Tebbe 2002 \\
\hline \multirow[t]{4}{*}{. protéine insecticide (Bt) } & Communautés bactériennes & Mineurs & Baumgarte et Tebbe 2005 \\
\hline & Détritivores (microorganismes, isopodes) & Mineurs & Escher et al. 2000 \\
\hline & $\begin{array}{l}\text { Vers de terre, nématodes, protozoaires, } \\
\text { bactéries, champignons }\end{array}$ & n.s. & Saxena et Stotzky 2001b \\
\hline & Ver de terre (Lumbricus terrestris) & n.s. & Zwahlen et al. 2003b² \\
\hline \multicolumn{4}{|l|}{ Lotus corniculatus } \\
\hline production d'opines & Microflore du sol & Mineurs & Oger et al. 1997, 2000 \\
\hline \multicolumn{4}{|l|}{ Nicotiana sylvestris } \\
\hline $\begin{array}{l}\text { protéine antifongique } \\
\text { (chitinase) }\end{array}$ & Symbiontes et agents phytopathogènes & n.s. & Vierheilig et al. 1993 \\
\hline \multicolumn{4}{|l|}{ Pomme de terre } \\
\hline gènes marqueurs & Communautés bactériennes & Mineurs & Lukow et al. 2000 \\
\hline protéine insecticide $(\mathrm{Bt})$ & Bactéries du sol et agents phytopathogènes & Mineurs & Donegan et al. 1996 \\
\hline $\begin{array}{l}\text { protéines insecticides } \\
\text { (lectines GNA et ConA) }\end{array}$ & Organismes du sol et processus biochimiques & Mineurs & Griffiths et al. 2000 \\
\hline protéine antimicrobienne & Communautés bactériennes & n.s. & Heuer et al. 2002 \\
\hline \multirow[t]{3}{*}{ (lysozyme) } & Bactéries bénéfiques & n.s. & Lottmann et al. 1999 \\
\hline & Bactéries indigènes et antagonistes & n.s. & Lottmann et al. 2000 \\
\hline & Bactéries antagonistes & n.s. & Lottmann et Berg 2001 \\
\hline \multicolumn{4}{|l|}{ Tabac } \\
\hline contenu en lignine & Microflore détritivore & Mineurs & Hopkins et al. 2001 \\
\hline . protéines antimicrobiennes & Symbiontes (champignons mycorhiziens) & Mineurs & Vierheilig et al. 1995 \\
\hline $\begin{array}{l}\text { protéine insecticide } \\
\text { (inhibiteur de protéases) }\end{array}$ & $\begin{array}{l}\text { Protozoaires, nématodes, microarthropodes, } \\
\text { respiration microbienne }\end{array}$ & n.s. & Donegan et al. 1997 \\
\hline
\end{tabular}

1 Effets mineurs: ajustements mineurs des populations liés en général à l'activité biologique de la protéine recombinante exprimée; n.s. : effets non significatifs.

2 Effets négligeables pendant 160 jours; effets négatifs significatifs sur le taux de croissance après cette période. 
des périodes suffisamment longues pour interagir avec les organismes du milieu.

Dans l'ensemble, les études publiées sur le sujet suggèrent toutefois un impact mineur des plantes transgéniques sur les populations du sol et les processus biochimiques qui leur sont associés (Tableau 2). Alors que les pratiques culturales et les choix variétaux ont une influence marquée sur la microflore (Buckley et Schmidt 2001; Clegg et al. 2003; Siciliano et al. 1998), les cultures transgéniques montrent en général des effets négligeables sur I'incidence relative des populations microbiennes et animales du sol, ou encore sur le déroulement de processus comme la respiration microbienne ou la décomposition de la matière organique (Kowalchuk et al. 2003). Sur une base comparative, plusieurs études démontraient en outre que des variables comme le climat, le site de culture, le génotype de la plante ou même son stade de développement ont un impact beaucoup plus marqué sur les populations du sol que I'utilisation ou non de variétés transgéniques exprimant des caractères recombinants spécifiques comme la résistance aux insectes, la résistance aux agents phytopathogènes ou la tolérance aux herbicides (Dunfield et Germida 2001; Griffiths et al. 2000; Gyamfi et al. 2002; Heuer et al. 2002; Lottmann et Berg 2001; Lukow et al. 2000).

Dans les années à venir, le développement de lignées transgéniques produisant des protéines à fonctions biologiques variées souvent moins spécifiques rendra néanmoins justifiée la poursuite des études sur les interactions entre les cultures modifiées et les organismes du sol. En pratique, la détection et la caractérisation des diverses interactions possibles seront facilitées par un raffinement parallèle des approches méthodologiques adaptées à l'étude des organismes du sol. Des procédures améliorées pour : (i) l'extraction des protéines recombinantes à partir d'échantillons de sol; (ii) I'identification des espèces microbiennes et animales résidantes; (iii) un échantillonnage tenant compte de I'hétérogénéité du sol; et (iv) le choix rationnel d'organismes modèles représentatifs du milieu considéré contribueront, en particulier, à une prise en compte plus fidèle des interactions possibles entre les lignées transgéniques et la composante biotique des sols (Jepson et al. 1994; Kowalchuk et al. 2003), essentielle au bon fonctionnement des écosystèmes (Motavalli et al. 2005).

\section{Impacts indirects sur les insectes prédateurs et parasitoïdes}

La grande complexité des relations trophiques établies dans le milieu justifiera en outre la poursuite des études sur les impacts indirects exercés par les cultures transgéniques (v. Fig. 1). Dans un écosystème agricole, la plante cultivée peut être vue comme le maillon central d'un réseau trophique à plusieurs niveaux impliquant non seulement des organismes herbivores, détritivores ou pollinisateurs, mais aussi de nombreuses espèces de niveaux trophiques supérieurs se nourrissant de ces organismes (Groot et Dicke 2002). Au champ, les cultures transgéniques pourront ainsi montrer des effets aussi bien sur les organismes se nourrissant de tissus végétaux (effets directs) que sur des organismes carnivores ou parasites établis dans le milieu (effets indirects).
De manière plus spécifique, les cultures transgéniques pourront montrer des effets indirects sur les organismes non ciblés : (i) en diminuant la quantité de nourriture disponible par leur impact négatif sur l'incidence des populations herbivores ou détritivores; (ii) en altérant la santé générale ou la qualité nutritionnelle de ces organismes herbivores; ou (iii) en interférant avec des fonctions métaboliques ou cellulaires précises suite au transit du caractère recombinant dans le continuum [plante hôte] - [herbivore/détritivore] - [prédateur/parasite]. Plusieurs études ont été menées en laboratoire pour évaluer les impacts indirects des variétés transgéniques Bt sur la croissance, le développement et la survie d'organismes variés, avec comme modèles différents insectes prédateurs et parasitoïdes mis en contact avec des proies herbivores nourries de matériel transgénique (Tableau 3). Dans plusieurs cas, les effets notés étaient négligeables, en lien avec I'action spécifique des toxines Cry contre les herbivores ciblés par les lignées à l'étude (Bernal et al. 2002a; Dogan et al. 1996; Dutton et al. 2002; Obrist et al. 2005; Ponsard et al. 2002; Riddick et Barbosa 2000; Schuler et al. 2001; Zwahlen et al. 2000). En revanche, des effets négatifs ont été notés dans plusieurs cas, aussi bien pour des insectes prédateurs (Dutton et al. 2002; Hilbeck et al. 1998; Ponsard et al. 2002; Raps et al. 2001; Riddick et Barbosa 1998) que pour des insectes parasitoïdes (Ashouri et al. 2001a; Bernal et al. 2002b; Prütz et Dettner 2004).

Selon les données disponibles, l'impact négatif des lignées Bt sur ces organismes serait lié à une mauvaise santé des proies (ou des hôtes) herbivores causée par l'ingestion de protéines Cry et à une baisse conséquente de leur qualité nutritionnelle. Un exemple éloquent à cet effet est celui de l'insecte prédateur Chrysoperla carnea Stephens [Neuroptera : Chrysopidae], dont les paramètres de développement sont affectés par des hybrides de maïs Bt exprimant la toxine Cry1Ab si le vecteur herbivore est un lépidoptère sensible à la toxine (Dutton et al. 2002; Hilbeck et al. 1998; Raps et al. 2001), mais ne sont pas affectés si l'insecte est nourri de proies insensibles à la toxine comme des pucerons, des thrips ou des acariens (Dutton et al. 2002; Lozzia et al. 1998; Obrist et al. 2005). Ces observations, supportées par des études comportementales démontrant la préférence du même prédateur pour des lépidoptères nourris de matériel végétal non transgénique (Meier et Hilbeck 2001) ou celle de l'insecte parasitoïde Cotesia plutellae Kurdjumov [Hymenoptera : Branocidae] pour des hôtes résistants à la toxine recombinante (Schuler et al. 1999, 2003), suggèrent que les effets indirects des variétés transgéniques $\mathrm{Bt}$ résulteraient plus d'une mauvaise qualité des proies (ou des hôtes) que d'un effet spécifique des toxines exprimées dans les plantes modifiées.

Cet effet diffus des lignées Bt sur les populations d'insectes prédateurs et parasitoïdes est aussi suggéré par des données collectées en champ. Si la migration d'organismes prédateurs en réponse à une faible densité de proies herbivores nourries de plantes Bt a été observée dans certains cas (Riddick et al. 1998), la plupart des études suggèrent plutôt des effets très limités sur les populations non visées (Al-Deeb et al. 2001; Jasinski et al. 2003; Liu et al. 2002; Ning et al. 2001; Sun 
Tableau 3. Impact des cultures transgéniques Bt sur la performance d'insectes prédateurs et parasitoïdes nourris de proies ou d'hôtes herbivores ingérant les lignées modifiées - Un sommaire des études récentes en conditions contrôlées

\begin{tabular}{|c|c|c|c|c|}
\hline Culture / toxine Bt & Ennemi naturel & Proie/hôte herbivore & Impact $^{1}$ & Référence \\
\hline Canola / Cry1Ac & Diaeretiella rapae ${ }^{3}$ & Myzus persicae & n.s. & Schuler et al. 2001 \\
\hline \multirow[t]{6}{*}{ Coton / Cry1Ac } & Copidosoma floridanum ${ }^{3}$ & Pseudoplusia includens & négatif & Baur et Boethel 2003 \\
\hline & Cotesia marginiventris ${ }^{3}$ & P. includens & négatif & Baur et Boethel 2003 \\
\hline & Geocoris punctipes ${ }^{2}$ & Spodoptera exigua & négatif & Ponsard et al. 2002 \\
\hline & Nabis sp. ${ }^{2}$ & S. exigua & n.s. & Ponsard et al. 2002 \\
\hline & Orius tristicolor $^{2}$ & S. exigua & négatif & Ponsard et al. 2002 \\
\hline & Zelus renardii ${ }^{2}$ & S. exigua & n.s. & Ponsard et al. 2002 \\
\hline \multirow[t]{11}{*}{ Maïs / Cry1Ab } & Chrysoperla carnea ${ }^{2}$ & Frankliniella tenuicornis & n.s. & Obrist et al. 2005 \\
\hline & & Spodoptera littoralis & négatif & Hilbeck et al. 1998 \\
\hline & & & & Raps et al. 2001 \\
\hline & & & & Dutton et al. 2002 \\
\hline & & Ostrinia nubilalis & négatif & Hilbeck et al. 1998 \\
\hline & & Tetranychus urticae & n.s. & Dutton et al. 2002 \\
\hline & & Rhopalosiphum padi & n.s. & Dutton et al. 2002 \\
\hline & & & & Lozzia et al. 1998 \\
\hline & Cotesia flavipes $^{3}$ & Chilo partellus & négatif & Prütz et Dettner 2004 \\
\hline & Orius majusculus $^{2}$ & Anaphothrips obscurus & n.s. & Zwahlen et al. 2000 \\
\hline & Parallorhogas pyralophagus ${ }^{3}$ & Eoreuma loftini & négatif & Bernal et al. 2002b \\
\hline Pomme de terre / & Aphidius nigripes ${ }^{3}$ & Macrosiphum euphorbiae & négatif & Ashouri et al. 2001a \\
\hline \multirow[t]{3}{*}{ Cry3A } & Coleomegilla maculata ${ }^{2}$ & Leptinotarsa decemlineata & négatif & Riddick et Barbosa 1998 \\
\hline & Hippodamia convergens ${ }^{2}$ & M. persicae & n.s. & Dogan et al. 1996 \\
\hline & Lebia grandis ${ }^{2}$ & L. decemlineata & n.s. & Riddick et Barbosa 2000 \\
\hline Riz / Cry1Ab & Cyrtorhinus lividipennis ${ }^{2}$ & Nilaparvata lugens & n.s. & Bernal et al. 2002a \\
\hline
\end{tabular}

1 Impact négatif sur la survie ou certains paramètres de développement (taux de développement, fécondité, etc.); n.s. : effets non significatifs.

2 Insecte prédateur (carnivore).

3 Insecte parasitoïde.

et al. 2002; Wold et al. 2001). Dans un contexte agricole, l'effet des cultures Bt serait en fait négligeable comparativement aux effets négatifs généralement observés sur les mêmes populations avec les insecticides de synthèse, qui montrent souvent un effet toxique plus étendu (Musser et Shelton 2003; Reed et al. 2001). À l'échelle des écosystèmes, cet impact négligeable des lignées Bt serait le résultat, en somme, de la spécificité d'action des toxines Cry et d'un effet tampon du milieu qui, par la diversité des espèces qu'il abrite, exercerait une pression limitée sur les populations carnivores et parasites en assurant la disponibilité d'une diversité de proies et d'hôtes herbivores.

\section{Spécificité des produits recombinants et mutagénèse insertionnelle}

Le développement en cours de lignées modifiées exprimant des protéines recombinantes à fonctions biologiques moins spécifiques rendra toutefois essentielle, dans les années à venir, la poursuite des études sur les impacts directs et indirects des cultures transgéniques sur les organismes du milieu. Des protéines comme les toxines Cry du Bt ou les enzymes de tolérance aux herbicides montrent une action contre des cibles moléculaires précises, mais d'autres protéines actuellement considérées pour la répression des herbivores nuisibles (Tableau 4), comme les lectines ou les inhibiteurs de protéases, montrent en revanche des spectres d'action plus étendus (Ferry et al. 2004; Michaud 2000; Romeis et al. 2003). Alors que I'activité insecticide des toxines Cry repose sur des interactions spécifiques avec des protéines réceptrices chez certains organismes cibles, des inhibiteurs de protéases pourraient par exemple réagir avec les protéases digestives d'une gamme d'organismes en interaction dans l'écosystème avec la plante modifiée ou l'herbivore cible se nourrissant de cette plante (Bouchard et al. 2003a, b; Brodsgaard et al. 2003; Burgess et al. 1996; Ferry et al. 2003, 2005; Malone et Burgess 2000; Malone et al. 2000). 
MICHAUD: IMPACT DES PROTÉINES RECOMBINANTES SUR L'ENVIRONNEMENT

Tableau 4. Quelques protéines actuellement considérées pour la mise au point de cultures transgéniques résistantes aux insectes herbivores et aux agents phytopathogènes

\begin{tabular}{ll}
\hline Protéine & Mode d'action \\
\hline Avidine & Séquestration d'une vitamine, la biotine, co-facteur de plusieurs enzymes \\
Chitinases & Dégradation de la chitine constituante de parois cellulaires variées \\
ß-glucanases & Dégradation des ß-glucanes constituants de parois cellulaires variées \\
Inhibiteurs de protéases & Inhibition des protéases impliquées dans la digestion des protéines alimentaires \\
Inhibiteurs d' $\alpha$-amylases & Inhibition des amylases impliquées dans la digestion des composés amidonnés \\
Lectines & Liaison à des glycanes variés et agglutination irréversible des structures cellulaires \\
Neuropeptides & Altération des fonctions neurologiques endogènes et neurotoxicité \\
\hline
\end{tabular}

Plusieurs études ont été menées en laboratoire pour estimer l'impact de lignées transgéniques exprimant des inhibiteurs de protéases ou des lectines sur la croissance, le développement et la survie des insectes prédateurs et parasitoïdes (Tableau 5). Comme pour les variétés $\mathrm{Bt}$, des effets négligeables ont été notés dans plusieurs cas (Bell et al. 2003; Bouchard et al. 2003a, b; Couty et al. 2001; Ferry et al. 2003; Graham et al. 2002; Schuler et al. 2001; Setamou et al. 2002a, b), mais des effets notables positifs ou négatifs - ont aussi été observés à plusieurs reprises (Bell et al. 2001; Birch et al. 1999; 2003; Down et al. 2003; Ferry et al. 2005; Tomov et al. 2003). Ces effets, qui pourraient s'expliquer en partie par une piètre qualité des proies herbivores suite à l'ingestion des protéines recombinantes, pourraient aussi résulter d'un effet d'interférence de ces molécules dans la chaîne trophique. Des études visant à mesurer l'impact d'une lignée de pomme de terre exprimant un inhibiteur de protéases du riz sur I'insecte prédateur Perillus bioculatus F. [Hemiptera : Pentatomidae] démontraient par exemple une inhibition des protéases digestives du prédateur compensée rapidement par la sécrétion de nouvelles protéases insensibles à l'inhibiteur recombinant (Bouchard et al. 2003a, b). Plus récemment, une autre étude décrivait les effets négatifs transitoires d'une lignée de canola exprimant un inhibiteur de protéases de la moutarde sur le taux de croissance du prédateur Pterostichus madidus F. [Coleoptera : Carabidae], compensés ensuite par un ajustement graduel du système protéolytique digestif de l'insecte (Ferry et al. 2005). Ces observations, qui illustraient la capacité remarquable de ces organismes à éluder l'effet de substances nocives ou antinutritives retrouvées dans la diète, mettaient aussi en évidence le mouvement possible des protéines recombinantes vers des niveaux trophiques supérieurs.

À ce stade, des travaux demeurent souhaitables pour une prise en compte plus précise des impacts associés aux différents facteurs recombinants en développement sur les organismes du milieu. Des protéines comme les lectines, les inhibiteurs de protéases, les chitinases ou des protéines hybrides intégrant les fonctions de plusieurs de ces protéines représentent un complément potentiel aux toxines Cry pour la répression des ravageurs herbivores (Brunelle et al. 2005; Fitches et al. 2004; Outchkourov et al. 2004; Urwin et al. 1998; Zhu-Salzman et al. 2003). Cependant, la mise au point de lignées végé- tales exprimant de telles protéines à spectre d'action étendu devra être accompagnée d'études approfondies sur leur degré de spécificité effectif à l'échelle des écosystèmes agricoles. Dans une perspective plus large, l'impact des protéines recombinantes ou celui de l'insertion des transgènes sur le métabolisme de la plante modifiée devront être considérés pour cerner d'éventuels effets dans le milieu suite à une modification tangible de sa composition. Une altération des fonctions cellulaires de la plante par l'action d'un inhibiteur de protéases recombinant inactivant ses protéases endogènes pourrait par exemple montrer des effets, positifs ou négatifs, sur sa capacité de résister à certains stress (Gutierez-Campos et al. 2001; Van der Vyver et al. 2003). De manière similaire, des contenus modifiés en lignine ou en certains composés organiques chez des hybrides de maïs $\mathrm{Bt}$, qui pourraient résulter d'un évènement de mutagénèse insertionnelle ou d'altérations du génome en culture in vitro, pourraient montrer un effet sur leur taux de décomposition dans le sol, indépendamment de l'activité du produit recombinant (Masoero et al. 1999; Saxena et Stotzky 2001a). La mise en évidence de tels phénomènes, dans les années à venir, pourrait expliquer certaines observations inattendues, comme les impacts variables de lignées transgéniques de pomme de terre exprimant une toxine du Bt ou un inhibiteur de protéases sur le puceron Macrosiphum euphorbiae Thomas [Homoptera : Aphididae], présumément insensible aux deux protéines (Ashouri et al. 2001b) et à l'abri de ces molécules en raison de son mode d'alimentation limité aux cellules du phloème (Raps et al. 2001).

\section{EN CONCLUSION}

En somme, les données scientifiques disponibles mettent en lumière aussi bien la grande complexité des interactions possibles entre les organismes du milieu et les cultures transgéniques que l'impact limité des lignées transgéniques actuelles en milieu agricole, où des pratiques culturales courantes comme la fertilisation, le labour ou la répression des mauvaises herbes montrent des effets très marqués sur l'incidence des populations résidantes. Si les impacts environnementaux de protéines comme les toxines Cry du Bt ou les enzymes de tolérance aux herbicides sont aujourd'hui assez bien circonscrits, des études exhaustives demeurent toutefois essentielles pour évaluer l'impact de plusieurs protéines 
Tableau 5. Impact des cultures transgéniques exprimant des inhibiteurs de protéases ou des lectines pour la résistance aux insectes herbivores sur la performance d'insectes prédateurs et parasitoïdes variés nourris de proies ou d'hôtes herbivores ingérant les lignées modifiées - un sommaire des études récentes

\begin{tabular}{|c|c|c|c|c|}
\hline Protéine insecticide & Ennemi naturel & Proie/hôte herbivore & Impact ${ }^{1}$ & Référence \\
\hline \multicolumn{5}{|l|}{ Inhibiteurs de protéases } \\
\hline . Canola 'MTI-2' & Pterostichus madidus ${ }^{2}$ & Plutella xylostella & négatif & Ferry et al. 2005 \\
\hline \multirow[t]{2}{*}{. Canola ‘OCl' } & Diaeretiella rapae ${ }^{3}$ & Myzus persicae & n.s. & Schuler et al. 2001 \\
\hline & Harmonia axyridis ${ }^{2}$ & P. xylostella & n.s. & Ferry et al. 2003 \\
\hline . Fraise 'CpTl' & Carabidés $^{\mathrm{b}}$ & Otiorynchus sulcatus & n.s. & Graham et al. 2002 \\
\hline \multirow[t]{2}{*}{ Pomme de terre 'CpTI' } & Eulophus pennicornis ${ }^{3}$ & Lacanobia oleracea & négatif & Bell et al. 2001 \\
\hline & Podisus maculiventris ${ }^{2}$ & L. oleracea & n.s. & Bell et al. 2003 \\
\hline \multirow[t]{2}{*}{ Pomme de terre ' $\mathrm{OCl}^{\prime}$} & Aphidius nigripes ${ }^{3}$ & Macrosiphum euphorbiae & positif & Ashouri et al. 2001a \\
\hline & Perillus bioculatus ${ }^{2}$ & Leptinotarsa decemlineata & n.s. & Bouchard et al. 2003a,b \\
\hline \multicolumn{5}{|l|}{ Lectines } \\
\hline \multirow[t]{2}{*}{. Canne à sucre 'GNA' } & Cotesia flavipes ${ }^{3}$ & Diatraea saccharalis & n.s. & Setamou et al. 2002a,b \\
\hline & Parallorhogas pyralophagus ${ }^{3}$ & Eoreuma loftini & négatif & Tomov et al. 2003 \\
\hline \multirow[t]{5}{*}{ Pomme de terre 'GNA' } & Adalia bipunctata ${ }^{2}$ & M. persicae & négatif & Down et al. 2003 \\
\hline & & & & Birch et al. 1999 \\
\hline & Aphidius ervi ${ }^{3}$ & M. persicae & n.s. & Couty et al. 2001 \\
\hline & Eulophus pennicornis ${ }^{3}$ & Lacanobia oleracea & positif & Bell et al. 2001 \\
\hline & Podisus maculiventris ${ }^{2}$ & L. oleracea & négatif & Bell et al. 2003 \\
\hline
\end{tabular}

recombinantes nouvellement considérées en phytoprotection ou à d'autres fins. Une compréhension accrue et une prise en compte systématique des phénomènes de mutagénèse insertionnelle et d'interférence métabolique chez les clones modifiés demeurent également nécessaires pour cerner les impacts associés aux protéines à large spectre d'action et pour élucider certains effets inattendus du processus de transgénèse sur les organismes du milieu ou sur la plante elle-même. Enfin, la poursuite des études sur l'impact agroenvironnemental des pratiques culturales liées aux lignées transgéniques demeure essentielle pour une utilisation optimale de ces plantes dans une optique de développement durable axé, entre autres, sur des modes de production respectueux du milieu et sur une gestion rationnelle des pesticides chimiques et des cultures prévenant l'apparition rapide de résistance génétique chez les organismes nuisibles (Glaser et Matten 2003; Shelton et al. 2002).

Alors qu'une description plus détaillée des effets propres aux cultures transgéniques demeure souhaitable, des études comparatives tenant compte des impacts de leurs contreparties conventionnelles apparaissent essentielles. L'évolution récente des systèmes agricoles, régie le plus souvent par des impératifs agroéconomiques plaçant la recherche de hauts rendements au cœur des développements, est à l'origine d'un ensemble de problèmes d'ordre envi- ronnemental comme la pollution du milieu par les engrais et les pesticides, l'émission de gaz toxiques dans I'atmosphère, I'apparition accélérée d'organismes nuisibles résistants aux pesticides, la rareté croissante des surfaces arables disponibles et la dégradation des sols par l'érosion ou la salinisation. L'impact environnemental des cultures transgéniques, dans ce contexte, doit être considéré d'une manière globale, à la lumière de l'ensemble des impacts réciproques associés aux méthodes de culture actuelles. Les variétés transgéniques tolérantes aux herbicides, par exemple, si elles contribuent à un mode d'agriculture axé sur la productivité, pourraient en revanche faciliter l'adoption de pratiques culturales comme le semis direct, permettre une baisse tangible de l'emploi des herbicides en milieu agricole et, sous certaines conditions, tempérer les effets négatifs du désherbage sur la biodiversité au champ (Dewar et al. 2003; Gianessi 2005; Phipps et Park 2002). L'adoption de ces cultures pourrait même contribuer, sur une échelle plus globale, à une diminution significative des besoins en énergie pour la fabrication, le transport et l'application des intrants agricoles, des opérations contribuant de surcroît aux émissions de gaz polluants dans I'atmosphère (Bennett et al. 2004). En définitive, la véritable question pour les années à venir au sujet de l'impact environnemental des cultures transgéniques n'est pas de déterminer si oui ou non elles montrent des impacts sur le milieu, mais plutôt d'évaluer les conséquences 
nettes de ces impacts à la lumière des défis environnementaux auxquels est confronté, déjà, le monde agricole.

\section{REMERCIEMENTS}

L'auteur remercie le Dr. Conrad Cloutier pour de nombreuses discussions sur plusieurs des thèmes abordés. Cette étude a été financée par une subvention de recherche du ministère du Développement durable, de I'Environnement et des Parcs du Québec (Projet PARDE 02-1).

\section{RÉFÉRENCES}

Al-Deeb, M.A., G.E. Wilde et R.A. Higgins. 2001. No effect of Bacillus thuringiensis corn and Bacillus thuringiensis on the predator Orius insidiosus (Hemiptera: Anthocoridae). Environ. Entomol. 30 : 625-629.

Armer, C.A., R.E. Berry et M. Kogan. 2000. Longevity of phytophagous heteropteran predators feeding on transgenic Btt-potato plants. Entomol. Exp. Appl. 95 : 329-333.

Ashouri, A., D. Michaud et C. Cloutier. 2001a. Unexpected effects of different potato resistance factors to the Colorado potato beetle (Coleoptera: Chrysomelidae) on the potato aphid (Homoptera: Aphididae). Environ. Entomol. 30 : 524-532.

Ashouri, A., D. Michaud et C. Cloutier. 2001b. Recombinant and classically selected factors of potato plant resistance to the Colorado potato beetle, Leptinotarsa decemlineata, variously affect the potato aphid parasitoid Aphidius nigripes. BioControl $46: 401-418$.

Baumgarte, S. et C.C. Tebbe. 2005. Field studies on the environmental fate of the Cry1Ab Bt-toxin produced by transgenic maize (MON810) and its effect on bacterial communities in the maize rhizosphere. Mol. Ecol. 14 : 2539-2551.

Baur, M.E. et D.J. Boethel. 2003. Effect of Bt-cotton expressing $\operatorname{Cry} 1 \mathrm{~A}(\mathrm{c})$ on the survival and fecundity of two hymenopteran parasitoids (Braconidae, Encyrtidae) in the laboratory. Biol. Control $26: 325-332$.

Bell, H.A., E.C. Fitches, G.C. Marris, J. Bell, J.P. Edwards, J.A Gatehouse et A.M. Gatehouse. 2001. Transgenic GNA expressing potato plants augment the beneficial biocontrol of Lacanobia oleracea (Lepidoptera: Noctuidae) by the parasitoid Eulophus pennicornis (Hymenoptera: Eulophidae). Transgenic Res. 10 : 35-42.

Bell, H.A., R.E. Down, E.C. Fitches, J.P. Edwards et A.M.R. Gatehouse. 2003. Impact of genetically modified potato expressing plant-derived insect resistance genes on the predatory bug Podisus maculiventris (Heteroptera: Pentatomidae). Biocontrol Sci. Technol. 13 : 729-741.

Bennett, R., R. Phipps, A. Strange et P. Grey. 2004. Environmental and human health impacts of growing genetically modified herbicide-tolerant sugar beet: a lifecycle assessment. Plant Biotechnol. J. 2 : 273-278.

Bernal, C.C., R.M. Aguda et M.B. Cohen. 2002a. Effect of rice lines transformed with Bacillus thuringiensis toxin genes on the brown planthopper and its predator Cyrtorhinus lividipennis. Entomol. Exp. Appl. 102 : 21-28.

Bernal, J.S., J.G. Griset et P.O. Gillogly. 2002b. Impacts of developing on Bt maize-intoxicated hosts on fitness parameters of a stem borer parasitoid. J. Entomol. Sci. $37: 27-40$

Birch, A.N.E., I.E. Geoghegan, M.E.N. Majerus, J.W. McNicol, C.A. Hackett, A.M.R. Gatehouse et J.A. Gatehouse. 1999. Tri-trophic interactions involving pest aphids, predatory 2spot ladybirds and transgenic potatoes expressing snowdrop lectin for aphid resistance. Mol. Breed. 5 : 75-83.
Bohan, D.A., C.W.H. Boffey, D.R. Brooks, S.J. Clark, A.M. Dewar, L.G. Firbank, A.J. Haughton, C. Hawes, M.S. Heard, M.J. May, J.L. Osborne, J.N. Perry, P. Rothery, D.B. Roy, R.J. Scott, G.R. Squire, I.P. Woiwod et G.T. Champion. 2005. Effects on weed and invertebrate abundance and diversity of herbicide management in genetically modified herbicide-tolerant winter-sown oilseed rape. Proc. R. Soc. B 272 : 463-474.

Borisjuk, N.V., L.G. Borisjuk, S. Logendra, F. Petersen, Y. Gleba et I. Raskin. 1999. Production of recombinant proteins in plant root exudates. Nat. Biotechnol. $17: 466-469$.

Bouchard, É., D. Michaud et C. Cloutier. 2003a. Molecular interactions between an insect predator and its herbivore prey on transgenic potato expressing a cysteine proteinase inhibitor from rice. Mol. Ecol. 12 : 2429-2437.

Bouchard, É., C. Cloutier et D. Michaud. 2003b. Oryzacystatin I expressed in transgenic potato induces digestive compensation in an insect natural predator via its herbivorous prey feeding on the plant. Mol. Ecol. 12 : 2439-2446.

Bourguet, D., J. Chaufaux, A. Micoud, M. Delos, B. Naibo, F. Bombarde, G. Marque, N. Eychenne et C. Pagliari. 2002. Ostrinia nubilalis parasitism and the field abundance of non-target insects in transgenic Bacillus thuringiensis corn (Zea mays). Environ. Biosafety Res. $1:$ 49-60.

Brodsgaard, H.F., C.J. Brodsgaard, H. Hansen et G.L. Lövei. 2003. Environmental risk assessment of transgene products using honey bee (Apis mellifera) larvae. Apidologie 34 : 139-145.

Brooks, D.R., D.A. Bohan, G.T. Champion, A.J. Haughton, C. Hawes, M.S. Heard et 27 co-auteurs. 2003. Invertebrate responses to the management of genetically modified herbicide-tolerant and conventional spring crops. I. Soilsurface-active invertebrates. Philos. Trans. R. Soc. Lond. B 358 : 1847-1862.

Bruinsma, M., G.A. Kowalchuk et J.A. van Veen. 2003. Effects of genetically modified plants on microbial communities and processus in soil. Biol. Fertil. Soils $37: 329$ 337.

Brunelle, F., C. Girard, C. Cloutier et D. Michaud. 2005. A hybrid, broad-spectrum inhibitor of Colorado potato beetle aspartate and cysteine digestive proteinases. Arch. Insect Biochem. Physiol. $60: 20-31$.

Buckley, D.H. et T.M. Schmidt. 2001. The structure of microbial communities in soil and the lasting impact of cultivation. Microb. Ecol. 42 : 11-21.

Burgess, E.P.J., L.A. Malone et J.T. Christeller. 1996. Effects of two proteinase inhibitors on the digestive enzymes and survival of honey bees (Apis mellifera). J. Insect Physiol. 42 : 823-828.

Candolfi, M.P., K. Brown, C. Grimm, B. Reber et H. Schmidli. 2004. A faunistic approach to assess potential sideeffects of genetically modified Bt-corn on non-target arthropods under field conditions. Biocontrol. Sci. Technol. $14: 129-170$.

Carter, M.E., M.G. Villani, L.L. Allee et J.E. Losey. 2004. Absence of non-target effects on two Bacillus thuringiensis coleopteran active delta-endotoxins on the bulb mite, Rhizoglypus robini (Claparede) (Acare, Acaridae). J. Appl. Entomol. 128 : 56-63.

CBD [Convention of Biological Diversity]. 1992. 'Preamble' and Article 2: Use of terms'. United Nations Environment Program (UNEP), Secretariat of the Convention on Biological Diversity. Montréal, Canada. [http://www. biodiv.org/doc/legal/cbd-en.pdf]

Champion, G.T., M.J. May, D. Bennett, D.R. Brooks, S.J. Clark, R.E. Daniels et 12 co-auteurs. 2003. Crop management and agronomic context of the farm scale evaluations of genetically modified herbicide-tolerant crops. Philos. Trans. R. Soc. Lond. B 358 : 1801-1818.

Clark, B.W., T.A. Phillips et J.R. Coats. 2005. Environmental fate and effects of Bacillus thuringiensis (Bt) proteins from transgenic crops: A review. J. Agric. Food Chem. 53 : 4643-4653. 
Clegg, C.D., R.D.L. Lovell et P.J. Hobbs. 2003. The impact of grassland management regime on the community structure of selected bacterial groups in soils. FEMS Microbiol. Ecol. 43 : 263-270.

Couty, A., R.E. Down, A.M.R. Gatehouse, L. Kaiser, M.H. Pham-Delègue et G.M. Poppy. 2001. Effects of artificial diet containing GNA and GNA-expressing potatoes on the development of the aphid parasitoid Aphidius ervi Haliday (Hymenoptera: Aphidiidae). J. Insect Physiol. 47 : 1357-1366.

Crecchio, C. et G. Stotzky. 1998. Insecticidal activity and biodegradation of the toxin from Bacillus thuringiensis subsp. kurstaki bound to humic acids from soil. Soil Biol. Biochem. 30 : 463-470.

Crecchio, C. et G. Stotzky. 2001. Biodegradation and insecticidal activity of the toxin from Bacillus thuringiensis subsp. kurstaki bound on complexes of montmorillonitehumic acids-Al hydroxypolymers. Soil Biol. Biochem. 33 573-581.

Dewar, A.M., M.J. May, I.P. Woiwod, L.A. Haylock, G.T. Champion, B.H. Garner, R.J.N. Sands, A. Qi et J.D. Pidgeon. 2003. A novel approach to the use of genetically modified herbicide tolerant crops for environmental benefit. Proc. R. Soc. Lond. B 270 : 335-340.

Dogan, E.B., R.E. Berry, G.L. Reed et P.A. Rossignol. 1996. Biological parameters of convergent lady beetles (Coleoptera: Coccinellidae) feeding on aphids (Homoptera: Aphididae) on transgenic potato. J. Econ. Entomol. 89 : 1105-1108.

Donegan, K.K., C.J. Palm, V.J. Fieland, L.A. Porteous, L.M Ganio, D.L. Schaller, L.Q. Bucao et R.J. Seidler. 1995. Changes in levels, species and DNA fingerprints of soil microorganisms associated with cotton expressing the Bacillus thuringiensis var. kurstaki endotoxin. Appl. Soi Ecol. 2 : 111-124.

Donegan, K.K., D.L. Schaller, J.K. Stone, L.M. Ganio, G. Reed, P.B. Hamm et R.J. Seidler. 1996. Microbial populations, fungal species diversity and plant pathogen levels in field plots of potato plants expressing the Bacillus thuringiensis var. kurstaki endotoxin. Transgenic Res. 5 : 25-35

Donegan, K.K., R.J. Seidler, V.J. Fieland, D.L. Schaller, C.J. Palm, L.M. Ganio, D.M. Cardwell et Y. Steinberger. 1997. Decomposition of genetically engineered tobacco under field conditions: persistence of the proteinase inhibitor product and effects on soil microbial respiration and protozoa, nematode and arthropod populations. J. Appl. Ecol. 34 : 767-777.

Donegan, K.K., R.J. Seidler, J.D. Doyle, L.A. Porteous, G. Digiovanni, F. Widmer et L.S. Watrud. 1999. A field study with genetically engineered alfalfa inoculated with recombinant Sinorhizobium meliloti: effect on the soil ecosystem. J. Appl. Ecol. 36 : 920-936.

Down, R.E., L. Ford, S.D. Woodhouse, G.M. Davison, M.E.N. Majerus, J.A. Gatehouse et A.M.R. Gatehouse. 2003. Tritrophic interactions between transgenic potato expressing snowdrop lectin (GNA), an aphid pest (peachpotato aphid; Myzus persicae (Sulz.)) and a beneficial predator (2-spot ladybird; Adalia bipunctata L.). Transgenic Res. 12 : 229-241.

Duan, J.J., G. Head, M.J. McKee, T.E. Nickson, J.W. Martin et F.S. Sayegh. 2002. Evaluation of dietary effects of transgenic corn pollen expressing Cry3Bb1 protein on a non-target ladybird beetle, Coleomegilla maculata. Entomol. Exp. Appl. 104 : 271-280.

Dunfield, K.E. et J.J. Germida. 2001. Diversity of bacterial communities in the rhizosphere and root interior of fieldgrown genetically modified Brassica napus. FEMS Microbiol. Ecol. 38 : 1-9.

Dunfield, K.E. et J.J. Germida. 2003. Seasonal changes in the rhizosphere microbial communities associated with field-grown genetically modified canola (Brassica napus). Appl. Environ. Microbiol. 69 : 7310-7318.
Dunfield, K.E. et J.J. Germida. 2004. Impact of genetically modified crops on soil- and plant-associated microbial communities. J. Environ. Qual. 33 : 806-815.

Dutton, A., H. Klein, J. Romeis et F. Bigler. 2002. Uptake of Bt-toxin in herbivores feeding on transgenic maize and consequences for the predator Chrysoperla carnea. Ecol. Entomol. 27 : 441-447.

Dutton, A., J. Romeis et F. Bigler. 2003. Assessing the risks of insect resistant transgenic plants on entomophagous arthropods: Bt-maize expressing Cry1 $\mathrm{Ab}$ as a case study. BioControl $48: 611-636$.

Ehrlich, P.R. et E.O. Wilson. 1991. Biodiversity studies science and policy. Science 253: 758-762.

Elmore, R.W., F.W. Roeth, L.A. Nelson, C.A. Shapiro, R.N. Klein, S.Z. Knezevic et A. Martin. 2001. Glyphosateresistant soybean cultivar yields compared with sister lines. Agron. J. 93 : 408-412.

EPA [United States Environmental Protection Agency]. 2000. Bt plant-pesticides biopesticides registration action document. [http://www.epa.gov/oscpmont/sap/2000/ october/brad3_sment.pdf]

Escher, N., B. Käch et W. Nentwig. 2000. Decomposition of transgenic Bacillus thuringiensis maize by microorganisms and woodlice Porcellio scaber (Crustacea: Isopoda). Basic Appl. Ecol. 1 : 161-169.

Felke, M., N. Lorenze et G.-A. Langenbruch. 2002. Laboratory studies on the effects of pollen from Bt-maize on larvae of some butterfly species. J. Appl. Entomol. 126 : 320-325.

Ferry, N.R., J.M. Raemaekers, M.E.N. Majerus, L. Jouanin, G. Port, J.A. Gatehouse et A.M.R. Gatehouse. 2003. Impact of oilseed rape expressing the insecticidal cysteine protease inhibitor oryzacystatin on the beneficial predator Harmonia axyridis (multicoloured Asian ladybeetle). Mol. Ecol. 12 : 493-504.

Ferry, N., M.G. Edwards, J.A. Gatehouse et A.M.R Gatehouse. 2004. Plant-insect interactions: molecular approaches to insect resistance. Curr. Opin. Biotechnol. $15: 155-161$.

Ferry, N., L. Jouanin, R. Ceci, E.A. Mulligan, K. Emami, J.A. Gatehouse et A.M.R. Gatehouse. 2005. Impact of oilseed rape expressing the insecticidal serine protease inhibitors, mustard trypsin inhibitor-2 on the beneficial predator Pterostichus madidus. Mol. Ecol. 14 : 337-349.

Firbank, L.G. 2003. Introduction. Philos. Trans. R. Soc. Lond. B 358 : 1777-1778.

Firbank, L.G., M.S. Heard, I.P. Woiwod, C. Hawes, A.J. Haughton, G.T. Champion, R.J. Scott, M.O. Hill, A.M Dewar, G.R. Squire, M.J. May, D.R. Brooks, D.A. Bohan, R.E. Daniels, J.L. Osborne, D.B. Roy, H.I.J. Black, P. Rothery et J.N. Perry. 2003. An introduction to the farmscale evaluations of genetically modified herbicide-tolerant crops. J. Appl. Ecol. 40 : 2-16.

Fitches, E., M.G. Edwards, C. Mee, E. Grishin, A.M.R Gatehouse, J.P. Edwards et J.A. Gatehouse. 2004. Fusion proteins containing insect-specific toxins as pest control agents: snowdrop lectin delivers fused insecticidal spider venom toxic to insect haemolymph following oral ingestion. J. Insect Physiol. 50 : 61-71.

Folmer, D.J., J.R. Grant, T.C. Milton et J. Back. 2002. Utilization of Bt corn residues by grazing steers and $\mathrm{Bt}$ corn silage and grain by growing beef cattle and lactating dairy cows. J. Anim. Sci. 80 : 1352-1361.

Freckleton, R.P., P.A. Stephens, W.J. Sutherland et A.R. Watkinson. 2004. Amelioration of biodiversity impacts of genetically modified crops: predicting transient versus long-term effects. Proc. R. Soc. Lond. B 271 : 325-331.

Garcia, M.A. et M.A. Altieri. 2005. Transgenic crops: implications for biodiversity and sustainable agriculture. Bull. Sci. Technol. Soc. 25 : 335-353.

Gatehouse, A.M.R., N. Ferry et R.J.M. Raemaekers. 2002. The case of the monarch butterfly: a verdict is returned. Trends Genet. $18: 249-251$. 
Gelvin, S.B. 2003. Agrobacterium-mediated plant transformation: the biology behind the "gene-jockeying" tool. Microbiol. Mol. Biol. Rev. 67 : 16-37.

Gianessi, L.P. 2005. Economic and herbicide use impacts of glyphosate-resistant crops. Pest Manag. Sci. 61 : 241-245.

Glaser, J.A. et S.R. Matten. 2003. Sustainability of insect resistance management strategies for transgenic Bt corn. Biotechnol. Adv. 22 : 45-69.

Gotsch, N. et P. Rieder. 1995. Biodiversity, biotechnology, and institutions among crops situation and outlook. J. Sustain. Agric. $5: 5-40$.

Graham, J., S.C. Gordon, K. Smith, R.J. McNicol et J.W. McNicol. 2002. The effect of the cowpea trypsin inhibitor in strawberry on damage by vine weevil under field conditions. J. Hortic. Sci. Biotechnol. 77 : 33-40.

Griffiths, B.S., I.E. Geoghegan et W.M. Robertson. 2000. Testing genetically engineered potato, producing the lectins GNA and Con A, on non-target soil organisms and processes. J. Appl. Ecol. 37 : 159-170.

Groot, A.T. et M. Dicke. 2002. Insect-resistant transgenic plants in a multi-trophic context. Plant J. $31: 387-406$

Gutierrez-Campos, R., J.A. Torres-Acosta, J.D.J. PérezMartinez et M.A. Gomez-Lim. 2001. Pleiotropic effects in transgenic tobacco plants expressing oryzacystatin I gene. HortScience 36 : 118-119.

Gyamfi, S., U. Pfeifer, M. Stierschneider et A. Sessitsch. 2002. Effects of transgenic glufosinate-tolerant oilseed rape (Brassica napus) and the associated herbicide application on eubacterial and Pseudomonas communities in the rhizosphere. FEMS Microbiol. Ecol. 41 : 181-190.

Hansen Jesse, L.C. et J.J. Obrycki. 2000. Field deposition of Bt transgenic corn pollen: lethal effects on the monarch butterfly. Oecologia $125: 241-248$.

Hardon, J., D. Duvick et B. Visser. 2000. Genetic diversity, conservation and development. Pages 1-8 in D. Almekinders et W. de Boef (éds.), Encouraging diversity: The conservation and development of plant genetic resources. Intermediate Technology Publications, Londres, G.-B.

Haughton, A.J., G.T. Champion, C. Hawes, M.S. Heard, D.R. Brooks, D.A. Bohan et al. 2003. Invertebrate responses to the management of genetically modified herbicidetolerant and conventional spring crops. II. Within-field epigeal and aerial arthropods. Philos. Trans. R. Soc. Lond. B 358 : 1863-1877.

Hawes, C., A.J. Haughton, J.L. Osborne, D.B. Roy, S.J. Clark, J.N. Perry et al. 2003. Responses of plants and invertebrate trophic groups to contrasting herbicide regimes in the farm scale evaluations of genetically modified herbicide-tolerant crops. Philos. Trans. R. Soc. Lond. B 358 : 1899-1913.

Head, G., C.R. Brown, M.E. Groth et J.J. Duan. 2001. Cry1Ab protein levels in phytophagous insects feeding on transgenic corn: implications for secondary exposure risk assessment. Entomol. Exp. Appl. 99 : 37-45.

Head, G., J.B. Surber, J.A. Watson, J.W. Martin et J.J. Duan. 2002. No detection of Cry1Ac protein in soil after multiple years of transgenic Bt cotton (Bollgard) use. Environ. Entomol. $31:$ 30-36.

Heard, M.S., C. Hawes, G.T. Champion, S.J. Clark, L.G. Firbank, A.J. Haughton et al. 2003a. Weeds in fields with contrasting conventional and genetically modified herbicide tolerant crops. I. Effects on abundance and diversity. Philos. Trans. R. Soc. Lond. B $358:$ 1819-1832.

Heard, M.S., C. Hawes, G.T. Champion, S.J. Clark, L.G. Firbank, A.J. Haughton et al. 2003b. Weeds in fields with contrasting conventional and genetically modified herbicide tolerant crops. II. Effects on individual species. Philos. Trans. R. Soc. Lond. B 358 : 1833-1846.

Hellmich, R.L., B.D. Siegfried, M.K. Sears, D.E. Stanley-Horn, M.J. Daniels, H.R. Mattila, T. Spencer, K.G. Bidne et L.C. Lewis. 2001. Monarch larvae sensitivity to Bacillus thuringiensis-purified proteins and pollen. Proc. Natl. Acad. Sci. USA 98 : 11925-11930.
Herman, R.A., J.D. Wolt et W.R. Halliday. 2002. Rapid degradation of the Cry1F insecticidal crystal protein in soil. J. Agric. Food Chem. 50 : 7076-7078.

Heuer, H., R.M. Kroppenstedt, J. Lottmann, G. Berg et K. Smalla. 2002. Effects of T4 lysozyme release from transgenic potato roots on bacterial rhizosphere communities are negligible relative to natural factors. Appl. Environ. Microbiol. 68 : 1325-1335.

Hilbeck, A., M. Baumgartner, P.M. Fried et F. Bigler. 1998. Effects of transgenic Bacillus thuringiensis corn-fed prey on mortality and development time of immature Chrysoperla carnea (Neuroptera: Chrysopidae). Environ. Entomol. 27 : 480-487.

Hopkins, D.W. et E.G. Gregorich. 2003. Detection and decay of the $\mathrm{Bt}$ endotoxin in soil from a field trial with genetically modified maize. Eur. J. Soil Sci. 54 : 793-800.

Hopkins, D.W., E.A. Webster, J.A. Chudek et C. Halpin. 2001. Decomposition in soil of tobacco plants with genetic modifications to lignin biosynthesis. Soil Biol. Biochem. $33: 1455-1462$

James, C.A. 2005. Global review of commercialized transgenic crops, 2005. ISAAA Briefs No. 32. International Service for the Acquisition of Agri-Biotech Applications, Ithaca, NY.

Jasinski, J.R., J.B. Eisley, C.E. Young, J. Kovach et H. Wilson. 2003. Select nontarget arthropod abundance in transgenic and nontransgenic field crops in Ohio. Environ. Entomol. 32 : 407-413.

Jenkins, R. 1992. Bringing Rio home: Biodiversity in our food and farming. The SAFE Alliance. Londres, G.-B. 30 pp.

Jepson, P.C., B.A. Croft et G.E. Pratt. 1994. Test systems to determine the ecological risks posed by toxin release from Bacillus thuringiensis genes in crop plants. Mol. Ecol. 3 : 81-89.

Kowalchuk, G.A., M. Bruinsma et J.A. van Veen. 2003. Assessing responses of soil microorganisms to $\mathrm{GM}$ plants. Trends Ecol. Evol. 18 : 403-410.

Kunin, W.E. et J.H. Lawton. 1996. Does biodiversity matter. Evaluating the case for conserving species. Pages 367 387 in K.J. Gaston (éd.), Biodiversity. A biology of numbers and difference. Blackwell Publishers, Oxford, G.-B.

Liu, Z.C., G.Y. Ye et C. Hu. 2002. Effects of Bt transgenic rice on population dynamics of main non-target insect pests and dominant spider species in rice paddies. Acta Phytophylacica Sin. 29 : 138-144.

Lockwood, J.A. 1999. Agriculture and biodiversity: finding our place in this world. Agric. Hum. Values $16: 365-379$.

Losey, J.E., L.S. Rayor et M.E. Carter. 1999. Transgenic pollen harms monarch larvae. Nature $399: 214$.

Losey, J.E., R.A. Hufbauer et R.G. Hartzler. 2003. Enumerating lepidopteran species associated with maize as a first step in risk assessment in the USA. Environ. Biosafety Res. 2 : 247-261.

Losey, J.E., J.J. Obrycki et R.A. Hufbauer. 2004a. Biosafety considerations for transgenic insecticidal plants: non-target herbivores, detritivors, and pollinators. Pages 153155 in Encyclopedia of Plant and Crop Science. Marcel Dekker Inc., New York.

Losey, J.E., J.J. Obrycki et R.A. Hufbauer. 2004b. Biosafety considerations for transgenic insecticidal plants: nontarget predators and parasitoids. Pages 156-159 in Encyclopedia of Plant and Crop Science. Marcel Dekker Inc., New York.

Lottmann, J. et G. Berg. 2001. Phenotypic and genotypic characterisation of antagonistic bacteria associated with roots of transgenic and non-transgenic potato plants. Microbiol. Res. 156 : 75-82.

Lottmann, J., H. Heuer, K. Smalla et G. Berg. 1999. Influence of transgenic T4-lysozyme-producing potato plants on potentially beneficial plant-associated bacteria. FEMS Microbiol. Ecol. 29 : 365-377. 
Lottmann, J., H. Heuer, J. de Vries, A. Mahn, K. Düring, W. Wackernagel, K. Smalla et G. Berg. 2000. Establishment of introduced antagonistic bacteria in the rhizosphere of transgenic potatoes and their effect on the bacterial community. FEMS Microbiol. Ecol. 33 : 41-49.

Lozzia, G.C. 1999. Biodiversity and structure of ground beetle assemblages (Coleoptera: Carabidae) in Bt corn and its effects on non target insects. Boll. Zool. Agrar. Bachic. $31: 37-58$.

Lozzia, G.C., C. Furlanis, B. Manachini et I.E. Rigamonti. 1998. Effects of Bt corn on Rhopalosiphum padi L. (Rhynchota: Aphididae) and on its predator Chrysoperla carnea Stephen (Neuroptera Chrysopidae). Boll. Zool. Agrar. Bachic. 30 : 153-164.

Lozzia, G.C., L.E. Rigamonti, B. Manachini et R. Rocchetti. 2000. Laboratory studies on the effects of transgenic corn on the spider mite Tetranychus urticae Koch. Boll. Zool. Agrar. Bachic. 32 : 35-47.

Lukow, T., P.F. Dunfield et W. Liesack. 2000. Use of T-RFLP technique to assess spatial and temporal changes in the bacterial community structure within an agricultural soil planted with transgenic and non-transgenic potato plants. FEMS Microbiol. Ecol. 32 : 241-247.

Lumbierres, B., R. Albajes et X. Pons. 2004. Transgenic Bt maize and Rhopalosiphum padi (Hom., Aphididae) performance. Ecol. Entomol. 29 : 309-317.

Lundgren, G.J. et N.R. Wiedenmann. 2002. Coleopteran-specific Cry3Bb toxin from transgenic corn pollen does not affect the fitness of a nontarget species, Coleomegilla maculata DeGeer (Coleoptera: Coccinellidae). Environ. Entomol. 31 : 1213-1218.

Malone, L.A. et E.P.J. Burgess. 2000. Interference of protease inhibitors on non-target organisms. Pages 91-103 in D. Michaud (éd.), Recombinant protease inhibitors in plants. Landes Bioscience/Eurekah.com, Georgetown TX. 241 pp.

Malone, L.A. et M.H. Pham-Delègue. 2001. Effects of transgene products on honey bees (Apis mellifera) and bumble bees (Bombus sp.). Apidologie 32 : 287-304.

Malone, L.A. et M.H. Pham-Delègue. 2002. Using proteins to assess the potential impacts of genetically modified plants on honey bees. Pages 290-311 in J. Devillers et M.H. Pham-Delègue (éds.), Honey bees - Estimating the environmental impact of chemicals. Taylor and Francis, London/New York.

Malone, L.A., E.P.J. Burgess, D. Stefanovic et H.S. Gatehouse. 2000. Effects of four protease inhibitors on the survival of worker bumblebees, Bombus terrestris $\mathrm{L}$. Apidologie 31 : 25-38.

Marroquin, L.D., D. Elyassnia, J.S. Griffitts, J.S. Feitelson et R.V. Aroian. 2000. Bacillus thuringiensis $(\mathrm{Bt})$ toxin susceptibility and isolation of resistance mutants in the nematode Caenorhabditis elegans. Genetics 155 : 1693-1699.

Masoero, F., M. Moschini, F. Rossi, A. Prandini et A. Pietri. 1999. Nutritive value, mycotoxin contamination and in vitro rumen fermentation of normal and genetically modified corn (Cry1A(b)) grown in northern Italy. Maydica 44 : 205-209.

McClintock, J.T., C.R. Schaffer et R.D. Sjoblad. 1995. A comparative review of the mammalian toxicity of Bacillus thuringiensis-based pesticides. Pestic. Sci. 45 : 95-105.

Meier, M.S. et A. Hilbeck. 2001. Influence of transgenic Bacillus thuringiensis corn-fed prey on prey preference of immature Chrysoperla carnea (Neuroptera: Chrysopidae). Basic Appl. Ecol. 2 : 35-44.

Michaud, D. 2000. Biotechnology Intelligence Unit Series 3 Recombinant protease inhibitors in plants. Landes Bioscience/Eurekah.com, Georgetown TX. 241 pp.

Michaud, D. 2005. Impact environnemental des cultures transgéniques. I. La migration des transgènes. Phytoprotection 86: 93-105.

Motavalli, P.P., R.J. Kremer, M. Fang et N.E. Means. 2005. Impact of genetically modified crops and their management on soil microbially mediated plant nutrient transformations. J. Environ. Qual. 33 : 816-824.
Musser, F.R. et A.M. Shelton. 2003. Bt sweet corn and selective insecticides: impacts on pests and predators. Hortic. Entomol. $96: 71-80$.

Ning, X.Z., Q.P. Song, X.H. Kong, H. Chen, J.W. Meng, Y.J. He et S.L. Zhang. 2001. A preliminary research on the regularity of population fluctuations of major insects and natural enemies in the field of Bt transgenic cotton in the Xinjiang regions. China Cotton $28: 12-13$.

O'Callaghan, M., T.R. Glare, E.P.J. Burgess et L.A. Malone. 2005. Effects of plants genetically modified for insect resistance on nontarget organisms. Annu. Rev. Entomol. $50: 271-292$.

Oberhauser, K.S., M.D. Prysby, H.R. Mattila, D.E. StanleyHorn, M.K. Sears, G. Dively, E. Olson, J.M. Pleasants W.F. Lam et R.L. Hellmich. 2001. Temporal and spatial overlap between monarch larvae and corn pollen. Proc. Natl. Acad. Sci. USA 98 : 11913-11918.

Obrist, L.B., H. Klein, A. Dutton et F. Bigler. 2005. Effects of Bt maize on Frankliniella tenuicornis and exposure of thrips predators to prey-mediated Bt toxin. Entomol. Exp. Appl. $115:$ 409-416.

OECD [Organisation for Economic Cooperation and Development]. 1996. Saving biological diversity: economical incentives. OECD, Paris, France. 156 pp.

Oger, P., A. Petit et Y. Dessaux. 1997. Genetically engineered plants producing opines alter their biological environment. Nat. Biotechnol. $15: 369-372$.

Oger, P., H. Mansouri et Y. Dessaux. 2000. Effect of crop rotation and soil cover on alteration of the soil microflora generated by the culture of transgenic plants producing opines. Mol. Ecol. 9 : 881-890.

OTA [US Congress Office of Technology Assessment]. 1988. Technologies to maintain biological diversity. Lippincott Co., Philadelphia, PA. 334 pp.

Outchkourov, N.S., W.J. de Kogel, G.L. Wiegers, M. Abrahamson et M.A. Jongsma. 2004. Engineered multidomain cysteine protease inhibitors yield resistance against western flower thrips (Frankliniella occidentalis) in greenhouse trials. Plant Biotechnol. J. 2 : 449-458.

Palm, C.J., K. Donegan, D. Harris et R.J. Seidler. 1994. Quantification in soil of Bacillus thuringiensis var. kurstaki d-endotoxin from transgenic plants. Mol. Ecol. 3 : 145151.

Perry, J.N., P. Rothery, S.J. Clark, M.S. Heard et C. Hawes. 2003. Design, analysis and statistical power of the FarmScale Evaluations of genetically-modified herbicide-tolerant crops. J. Appl. Ecol. 40 : 17-31.

Pham-Delègue, M.H., L. Jouanin et J.C. Sandoz. 2002. Direct and indirect effects of genetically modified plants on the honey bee. Pages 312-326 in J. Devillers et M.H. PhamDelègue (éds.), Honey bees - Estimating the environmental impact of chemicals. Taylor and Francis, London/New York.

Phipps, R.H. et J.R. Park. 2002. Environmental benefits of genetically modified crops: global and European perspectives on their ability to reduce pesticide use. J. Anim. Feed Sci. 11: 1-18.

Pilcher, C.D., M.E. Rice, J.J. Obrycki et L.C. Lewis. 1997a. Field and laboratory evaluations of transgenic Bacillus thuringiensis corn on secondary Lepidopteran pests (Lepidoptera: Noctuidae). J. Econ. Entomol. 90 : 669-678.

Pilcher, C.D., J.J. Obrycki, M.E. Rice et L.C. Lewis. 1997b. Preimaginal development, survival, and field abundance of insect predators on transgenic Bacillus thuringiensis corn. Environ. Entomol. 26 : 446-454.

Pimentel, D.S. et P.H. Raven. 2000. Bt corn pollen impacts on nontarget Lepidoptera: assessment of effects in nature. Proc. Natl. Acad. Sci. USA 97 : 8198-8199.

Pimentel, D., C. Wilson, C. McCullum, R. Huang, P. Dwen, J. Flack, Q. Tran, T. Saltman et B. Cliff. 1997. Economic and environmental benefits of biodiversity. Bioscience 47 : 1-16. 
Pleasants, J.M., R.L. Hellmich, G.P. Dively, M.K. Sears, D.E. Stanley-Horn, H.R. Mattila, J.E. Foster, T.L. Clark et G.D. Jones. 2001. Corn pollen deposition on milkweeds in and near cornfields. Proc. Natl. Acad. Sci. USA 98 : 1191911924.

Ponsard, S., A.P. Gutierrez et N.J. Mills. 2002. Effect of Bttoxin (Cry1Ac) in transgenic cotton on the adult longevity of four Heteropteran predators. Environ. Entomol. 31 : $1197-1205$

Pretty, J.N. 1995. Regenerating agriculture. Policies and practice for sustainability and self-reliance. Earthscan Publications, Londres, G.-B. 320 pp.

Prütz, G. et K. Dettner. 2004. Effect of Bt corn leaf suspension on food consumption by Chilo partellus and life history parameters of its parasitoid Cotesia flavipes under laboratory conditions. Entomol. Exp. Appl. 111: 179-187.

Raps, A., J. Kehr, P. Gugerli, W.J. Moar, F. Bigler et A. Hilbeck. 2001. Immunological analysis of phloem sap of Bacillus thuringiensis corn and of the non-target herbivore Rhopalosiphum padi (Homoptera: Aphididae) for the presence of Cry1Ab. Mol. Ecol. 10 : 525-533.

Reed, G.L., A.S. Jensen, J. Riebe, G. Head et J.J. Duan. 2001. Transgenic Bt potato and conventional insecticides for Colorado potato beetle management: comparative efficacy and non-target impacts. Entomol. Exp. Appl. 100 : 89100.

Riddick, E.W. et P. Barbosa. 1998. Impact of Cry3A-intoxicated Leptinotarsa decemlineata (Coleoptera: Chrysomelidae) and pollen on consumption, development, and fecuntidy of Coleomegilla maculata (Coleoptera: Coccinellidae). Ann. Entomol. Soc. Am. 91 : 303-307.

Riddick, E.W. et P. Barbosa. 2000. Cry3A-intoxicated Leptinotarsa decemlineata (Say) are palatable prey for Lebia grandis Hentz. J. Entomol. Sci. 35 : 342-346.

Riddick, E.W., G. Dively et P. Barbosa. 1998. Effect of a seedmix deployment of Cry3A transgenic and nontransgenic potato on the abundance of Lebia grandis (Coleoptera: Carabidae) and Coleomegilla maculata (Coleoptera: Coccinellidae). Ann. Entomol. Soc. Am. 91 : 647-653.

Robinson, R.A. et W.J. Sutherland. 2002. Post-war changes in arable farming and biodiversity in Great Britain. J. Appl. Ecol. 39 : 157-176.

Romeis, J., D. Babendreier et F.L. Wackers. 2003. Consumption of snowdrop lectin (Galanthus nivalis agglutinin) causes direct effects on adult parasitic wasps. Oecologia $134:$ 528-536.

Roy, D.B., D.A. Bohan, A.J. Houghton, M.O. Hill, J.L. Osborne, S.J. Klark et al. 2003. Invertebrates and vegetation of field margins adjacent to crops subject to contrasting herbicide regimes in the Farm Scale Evaluations of genetically modified herbicide-tolerant crops. Philos. Trans. R. Soc. Lond. B 358 : 1879-1898.

Saxena, D. et G. Stotzky. 2001a. Bt corn has a higher lignin content than non-Bt corn. Am. J. Bot. 88 : 1704-1706.

Saxena, D. et G. Stotzky. 2001b. Bacillus thuringiensis (Bt) toxin released from root exudates and biomass of Bt corn has no apparent effect on earthworms, nematodes, protozoa, bacteria and fungi in soil. Soil Biol. Biochem. 33 : $1225-1230$

Saxena, D., S. Flores et G. Stotzky. 1999. Transgenic plants: insecticidal toxins in root exudates from Bt corn. Nature $402: 480$.

Saxena, D., S. Flores et G. Stotzky. 2002. Bt toxin is released in root exudates from 12 transgenic corn hybrids representing three transformation events. Soil Biol. Biochem. $34: 133-137$

Saxena, D., C.N. Stewart, I. Altosaar, Q.Y. Shu et G. Stotzky. 2004. Larvicidal Cry proteins from Bacillus thuringiensis are released in root exudates of transgenic $B$. thuringiensis corn, potato, and rice but not of $B$. thuringiensis canola, cotton, and tobacco. Plant Physiol. Biochem. 42 : 383-387.
Schmalenberger, A. et C.C. Tebbe. 2002. Bacterial community composition in the rhizosphere of a transgenic, herbicide-resistant maize (Zea mays) and comparison to its non-transgenic cultivar Bosphore. FEMS Microbiol. Ecol. $40: 29-37$.

Schmalenberger, A. et C.C. Tebbe. 2003. Genetic profiling of non-cultivated bacteria from the rhizospheres of sugar beet (Beta vulgaris) reveal field and annual variability but no effect of a transgenic herbicide resistance. Can. J. Microbiol. $49: 1-8$.

Schuler, T.H., P.J. Potting, I. Denholm et G.M. Poppy. 1999. Parasitoid behavior and Bt plants. Nature 400 : 825-826.

Schuler, T.H., I. Denholm, L. Jouanin, S.J. Clark, A.J. Clark et G.M. Poppy. 2001. Population-scale laboratory studies of the effect of transgenic plants on nontarget insects. Mol. Ecol. 10 : 1845-1853.

Schuler, T.H., R.P.J. Potting, I. Denholm, S.J. Clark, C.N. Stewart et G.M. Poppy. 2003. Tritrophic choice experiments with Bt plants, the diamondback moth (Plutella xylostella) and the parasitoid Cotesia plutellae. Transgenic Res. $12: 351-361$.

Sears, M.K., R.L. Hellmich, D.E. Stanley-Horn, K.S. Oberhauser, J.M. Pleasants, H.R. Mattila, B.D. Sigfried et G.P. Dively. 2001. Impact of Bt corn pollen on monarch butterfly populations: a risk assessment. Proc. Natl. Acad. Sci. USA 98 : 11937-11942.

Setamou, M., J.S. Bernal, J.C. Legaspi et T.E. Mirkov. 2002a. Effects of snowdrop lectin (Galanthus nivalis agglutinin) expressed in transgenic sugarcane on fitness of Cotesia flavipes (Hymenoptera: Braconidae), a parasitoid of the non-target pest Diatraea saccharalis (Lepidoptera: Crambidae). Ann. Entomol. Soc. Am. 95 : 75-83.

Setamou, M., J.S. Bernal, J.C. Legaspi et T.E. Mirkov. 2002b. Parasitism and location of sugarcane borer (Lepidoptera: Pyralidae) by Cotesia flavipes (Hymenoptera: Braconidae) on transgenic and conventional sugarcane. Environ. Entomol. 31 : 1219-1225.

Shelton, A.M. et M.K. Sears. 2001. The monarch butterfly controversy: scientific interpretations of a phenomenon. Plant J. 27 : 483-488.

Shelton, A.M., J.-Z. Zhao et R.T. Roush. 2002. Economic, ecological, food safety, and social consequences of the deployment of Bt transgenic plants. Annu. Rev. Entomol. $47: 845-881$.

Siciliano, S.D. et J.J. Germida. 1999. Taxonomic diversity of bacteria associated with the roots of field-grown transgenic Brassica napus cv. Quest, compared to the nontransgenic $B$. napus cv. Excel and $B$. rapa cv. Parkland. FEMS Microbiol. Ecol. 29 : 263-272.

Siciliano, S.D., C.M. Theoret, J.R. de Freitas, P.C. Hucl et J.J. Germida. 1998. Differences in the microbial communities associated with the roots of different cultivars of canola and wheat. Can. J. Microbiol. 44 : 844-851.

Sims, S.R. 1995. Bacillus thuringiensis var. kurstaki [CrylA(c)] protein expressed in transgenic cotton: effects on beneficial and other non-target insects. Southwest. Entomol. $20: 493-500$

Sims, S.R. 1997. Host activity spectrum of the CryllA Bacillus thuringiensis subsp. kurstaki protein: effect on Lepidoptera, Diptera, and non-target arthropods. Southwest. Entomol. 22 : 395-404.

Sims, S.R. et L.R. Holden. 1996. Insect bioassay for determining soil degradation of Bacillus thuringiensis subsp. kurstaki Cry1A(b) protein in corn tissue. Environ. Entomol. $25: 659-664$.

Sims, S.R. et J.W. Martin. 1997. Effect of the Bacillus thuringiensis insecticidal proteins $B \operatorname{CrylA}(b), \operatorname{Cryl} A(c)$, CryllA, and CryllIA on Folsomia candida and Xenylla grisea (Insecta: Collembola). Pedobiologia 41 : 412-416.

Sims, S.R. et J.E. Ream. 1997. Soil inactivation of the Bacillus thuringiensis subsp. kurstaki CryllA insecticidal protein within transgenic cotton tissue: laboratory and field studies. J. Agric. Food Chem. 45 : 1502-1505. 
Solbrig, O.T. 1992. Biodiversity: an introduction. Pages 71-82 in O.T. Solbrig, H.M. van Emden et P.G.W.J. van Oordt (éds.), Biodiversity and global change. International Union of Biological Sciences, Paris, France.

Stanley-Horn, D.E., G.P. Dively, R.L. Hellmich, H.R. Mattila, M.K. Sears, R. Rose, L.C.J. Jesse, J.E. Losey, J.J. Obrycki et L. Lewis. 2001. Assessing the impact of Cry1Abexpressing corn pollen on monarch butterfly larvae in field studies. Proc. Natl. Acad. Sci. USA 98 : 11931-11936.

Sun, C.G., J. Xu, Q.W. Zhang, H.B. Feng, F. Wang et R. Song. 2002. Effect of transgenic Bt cotton on population of cotton pests and their natural enemies in Xinjiang. Chinese J. Biol. Control $18: 106-110$.

Tapp, H. et G. Stotzky. 1998. Persistence of the insecticidal toxin from Bacillus thuringiensis subsp. kurstaki from soil. Soil Biol. Biochem. 30 : 471-476.

ten Kate, K. et S.A. Laird. 1999. The commercial use of biodiversity. Access to genetic resources and benefit-sharing. Earthscan Publications, Londres, G.-B. 400 pp.

Tomov, B.W., J.S. Bernal et S.B. Vinson. 2003. Impacts of transgenic sugarcane expressing GNA lectin on parasitism of Mexican rice borer by Parallorhogas pyralophagus (Marsh) (Hymenoptera: Braconidae). Environ. Entomol. 32 : 866-872.

Tschenn, J., J.E. Losey, L.H. Jesse, J.J. Obrycki, et R. Hufbauer. 2001. Effects of corn plants and corn pollen on monarch butterfly (Lepidoptera: Danaidae) oviposition behavior. Environ. Entomol. 30 : 495-500.

Urwin, P., M.J. McPherson et H.J. Atkinson. 1998. Enhanced transgenic plant resistance to nematodes by dual proteinase inhibitor constructs. Planta 204 : 472-479.

Van der Vyver, C., J. Schneidereit, S. Driscoll, J. Turner, K. Kunert et C.H. Foyer. 2003. Oryzacystatin I expression in transformed tobacco produces a conditional growth phenotype and enhances chilling tolerance. Plant Biotechnol. J. $1: 101-112$

Vierheilig, H., M. Alt, J.-M. Neuhaus, T. Boller et A. Wiemken. 1993. Colonization of transgenic Nicotiana sylvestris plants, expressing different forms of Nicotiana tabacum chitinase, by the root pathogen Rhizoctonia solani and by the mycorrhizal symbiont Glomus mosseae. Mol. Plant-Microbe Interact. 6 : 261-264.

Vierheilig, H., M. Alt, J. Lange, M. Gut-Rella, A. Wiekken et T. Boller. 1995. Colonization of transgenic tobacco constitutively expressing pathogenesis-related proteins by the vesicular-arbuscular mycorrhizal fungus Glomus mosseae. Appl. Environ. Microbiol. 61 : 3031-3034.
Watkinson, A.R., R.P. Freckleton, R.A. Robinson et W.J. Sutherland. 2000. Prediction of biodiversity response to genetically modified herbicide-tolerant crops. Science 289 : 1554-1557.

Wilson, J.D., A.J. Morris, B.E. Arroyo, S.C. Clark et R.B. Bradbury. 1999. A review of the abundance and diversity of invertebrate and plant foods of granivorous birds in northern Europe in relation to agricultural change. Agric. Ecosyst. Environ. 75 : 13-30.

Wold, S., E.C. Burkness, W.D. Hutchinson et R.C. Venette. 2001. In-field monitoring of beneficial insect populations in transgenic corn expressing a Bacillus thuringiensis toxin. J. Entomol. Sci. 36 : 177-186.

Wolt, J.D., R.K.D. Peterson, P. Bystrak et T. Meade. 2003. A screening level approach for nontarget insect risk assessment: transgenic Bt corn pollen and the monarch butterfly (Lepidoptera: Danaidae). Environ. Entomol. 32 : 237 246.

Wraight, C.L., A.R. Zangerl, M.J. Carroll et M.R. Berenbaum. 2000. Absence of toxicity of Bacillus thuringiensis pollen to black swallowtails under field conditions. Proc. Natl. Acad. Sci. USA 97 : 7700-7703.

Zangerl, A.R., D. McKenna, C.L. Wraight, M. Carroll, P. Ficarello, R. Warner et M.R. Berenbaum. 2001. Effects of exposure to event 176 Bacillus thuringiensis corn pollen on monarch and black swallowtail caterpillars under field conditions. Proc. Natl. Acad. Sci. USA 98 : 11908-11912.

Zhu-Salzman, K., J.-E. Ahn, R.A. Salzman, H. Koiwa, H. Shade et S. Balfe. 2003. Fusion of a soybean cysteine protease inhibitor and a legume lectin enhances antiinsect activity synergistically. Agric. For. Entomol. 5 : 317323.

Zwahlen, C., W. Nentwig, F. Bigler et A. Hilbeck. 2000. Tritrophic interactions of transgenic Bacillus thuringiensis corn, Anaphothrips obscurus (Thysanoptera: Thripidae), and the predator Orius majusculus (Heteroptera: Anthocoridae). Environ. Entomol. 29 : 846-850.

Zwahlen, C., A. Hilbeck, P. Gugerli et W. Nentwig. 2003a. Degradation of the Cry1Ab protein within transgenic Bacillus thuringiensis corn tissue in the field. Mol. Ecol. $12: 765-775$

Zwahlen, C., A. Hilbeck, R. Howald et W. Nentwig. 2003b. Effects of transgenic Bt corn litter on the earthworm Lumbricus terrestris. Mol. Ecol. 12 : 1077-1082. 